Research Article

\title{
Natural Frequencies and Mode Shapes of Drill Pipe in Subsea Xmas Tree Installation
}

\author{
Wensheng Xiao $\mathbb{D}^{1},{ }^{1}$ Haozhi Qin $\mathbb{D}^{1},{ }^{1}$ Jian Liu, ${ }^{1}$ Qi Liu, ${ }^{1}$ Junguo Cui, ${ }^{1}$ and Fengde Wang ${ }^{2}$ \\ ${ }^{1}$ College of Mechanical and Electronic Engineering, China University of Petroleum (East China), Qingdao, \\ Shandong 266580, China \\ ${ }^{2}$ College of Mechanical and Electronic Engineering, Shandong University of Science and Technology, Qingdao 266590, China \\ Correspondence should be addressed to Haozhi Qin; qinhao_zhi@163.com
}

Received 7 January 2020; Revised 18 March 2020; Accepted 17 April 2020; Published 14 May 2020

Academic Editor: Jian Li

Copyright (c) 2020 Wensheng Xiao et al. This is an open access article distributed under the Creative Commons Attribution License, which permits unrestricted use, distribution, and reproduction in any medium, provided the original work is properly cited.

\begin{abstract}
In this study, experimental and numerical investigations on the vibration characteristics of a drill pipe during the lowering of a subsea Xmas tree were presented. A fourth-order partial differential equation with variable coefficients was established based on Euler-Bernoulli beam theory. The natural frequencies and mode shapes are obtained by using the differential transformation method. Four drill pipe models of different sizes were used in the experiments which were measured using piezoelectric acceleration sensors and fiber Bragg grating sensors, respectively. The factors that affect the natural frequencies and mode shapes, such as length, diameter, lumped mass, and boundary conditions, were analyzed. The results show that all factors have remarkable effects on the natural frequency, but changes in the length and diameter of the pipe have little effect on the mode shapes; the main factors affecting the mode shape are the boundary conditions and lumped mass. The results of the numerical calculation were validated by a comparison with the experimental results and showed good agreement.
\end{abstract}

\section{Introduction}

A subsea Xmas tree (hereafter referred to simply as a tree) is a key piece of equipment in a subsea production system and is widely used in deep water [1]. The installation cost and installation risk in deep water have risen rapidly relative to those in shallow water due to the complex combination of waves and currents [2]. A deep water drill pipe (hereafter referred to simply as a pipe), which is a slender and elastic cylinder, may experience vortex-induced vibration (VIV) exerted by currents and waves. Such vibrations due to vortex shedding lead to cyclic stresses and could result in fatigue damage [3]. In order to improve the service life of the drill pipe, the natural frequency of the system is usually separated from the excitation frequency. Therefore, it is necessary to predict the natural frequency and mode shape of the pipe.

The power series method, the Wentzel-KramersBrillouin (WKB) method, the dynamic stiffness method, the variable conversion technique, and other numerical methods have been applied to calculate the vibration characteristics of cylindrical structures such as the pipe or marine risers. Dareing and Huang [3] used the power series method to solve the vibration partial differential equation and obtained an approximate solution for the frequencies of the riser operating in water depths up to $600 \mathrm{ft}$. Soltanahmadi [4] presented a method based on Fourier analysis to determine the natural frequencies of systems containing either single and multiple flexible risers from the numerically predicted results; this method showed good results in comparison with the linearization method studied by Triantafyllou and Bliek [5]. A simplified analytical approach was proposed by Sparks [6] to examine the physics of the transverse modal vibrations of risers induced by VIV; he believed the flexural rigidity (EI) generally has a small influence on the natural frequency of deep water riser in the low-frequency domain. Considering internal flows, Krawczyk [7] used the Galerkin finite element method to find the fundamental natural frequencies for various internal 
flows by neglecting the flexural stiffness of the riser; it was also found that the fundamental natural frequency decreases as the velocity of the internal fluid increases. MontoyaHernández et al. [8] presented a numerical algorithm to evaluate the natural frequency of marine production risers under internal multiphase flow, in which the riser behavior is affected by the internal fluid density. The solution of the nonlinear partial differential equation involves variable coefficients that cause research on the dynamic responses of marine risers to be highly complex [9], as it is evident in equation (1) later in this paper. In previous research, authors usually simplified the governing equation by ignoring the flexural rigidity and assuming a uniform tension. Although this method is considered to be effective, the accuracy of this approach was found to be limited to low-mode frequencies.

In addition to practical marine engineering researchers, theoretical researchers have focused on the vibration analysis of tensioned beams. Howson and Williams [10] presented a convenient dynamic stiffness matrix method to analyze the natural frequencies of Timoshenko beam under constant tension. The WKB-based dynamic stiffness method [11] has been applied to study the nonuniform marine risers based on the assumption that the properties within risers slowly vary. Based on the Wittrick-Williams algorithm, $\mathrm{Si}$ et al. [12] presented a new Newton-type method for nonlinear eigenvalue problems that results in secure secondorder convergence at natural frequencies and on mode vectors. Xi et al. [13] investigated the free transverse vibrations of standing and hanging Rayleigh beam-columns subjected to a vertically orientated gravity load; by seeking a nontrivial solution of the partial differential equation of motion for the transverse deflection, the natural frequencies and mode shapes of the beam-columns were calculated. In addition, through both experimental and theoretical analyses, Virgin et al. [14] confirmed that the natural frequencies of very slender vertical cantilevers are affected by their orientation due to gravity. In addition, Anye and Ziguo [15] transformed the fourth order differential equation of a Rayleigh beam into a second-order Fredholm integral equation and obtained the frequency equation by the integral equation method.

The differential transformation method (DTM) is particularly effective when solving the initial and boundary value problem of the nonlinear partial differential equations [16], and thus has been used with some success in applied mathematics in recent years. The DTM, a transformation technique based on Taylor series expansion, is used to solve the ordinary and partial differential equation approximately [17]. This method reduces the governing differential equation and the boundary conditions to a set of algebraic equations according to certain transformation rules. Hence, the DTM is treated as an iterative procedure to get higher order series. Mei [18] applied DTM to analyze the free lateral vibrations of a centrifugally stiffened rotating Euler-Bernoulli beam and obtained the natural frequencies and mode shapes. Ho and Chen [19] solved the free and forced vibration problems of a general elastically end-restrained nonuniform beam resting on a nonhomogeneous elastic foundation and subjected to axial tensile and transverse forces. Chen et al. [9] used the DTM to calculate the natural frequency of a marine riser and compared their findings with the numerical and experimental results obtained by other methods.

Regarding the vibrations of circular slender rod-like structures such as marine risers or drill pipes, most previous studies used boundary conditions in which the ends are fixed or hinged. In recent years, scholars have performed many studies on the vibration characteristics of cylindrical structures such as drill risers or drill pipes; however, most of these investigations focused on risers in working environments, whereas the vibration characteristics of risers or pipes during the installation process have not been frequently reported.

In this paper, the DTM is applied to solve the vibration problems of a suspended pipe. The governing differential equation is transformed into a recursive algebraic equation, and the boundary conditions are also transformed into simple algebraic equations. Thus, the difficulty of solving governing differential equation is greatly reduced. Furthermore, the analytical model is validated by comparing the experimentally measured natural frequencies of a marine riser model with the predicted ones.

\section{Mathematical Model}

2.1. Governing Equation. In the process of installing a tree, the top of the pipe is connected with a vessel through rigid coupling [20], and the bottom is connected to the tree as a lumped mass. The pipe is subjected to the axial tension force generated by the self-weight and the tree weight and also the lateral force generated by the combined action of wave and current, as shown in Figure 1(a).

To conveniently calculate and derive the formula, the following assumptions are applied during the deduction of the governing equation:

(i) The material of the drill pipe is linearly elastic, isotropous, and homogeneous.

(ii) The outer pipe diameter is constant.

(iii) The mechanical characteristics of the pipe are measured under large deformation with a small strain:

$$
\begin{aligned}
& \frac{\partial^{2}}{\partial z^{2}}\left(E(x) I(x) \frac{\partial^{2} x(z, t)}{\partial z^{2}}\right)-\frac{\partial}{\partial z}\left(T(z) \frac{\partial x(z, t)}{\partial z}\right) \\
& \quad+m_{\mathrm{e}}(z) \frac{\partial^{2} x(z, t)}{\partial t^{2}}=0 .
\end{aligned}
$$

In equation (1), $t$ is the time; $z$ is the coordinate measured along the axis of the pipe; $x(z, t)$ is the transverse deflection of the beam axis and is a function of the vertical coordinate $z$ and time $t ; E(x)$ is the modulus of elasticity; $I(x)$ is the area moment of inertia; $m_{\mathrm{e}}(z)$ is the effective mass of the pipe per unit length; and $T(z)$ is the axial tension force of the beam.

For a hang-off drilling pipe, $T(z)$ can be represented by the following: 


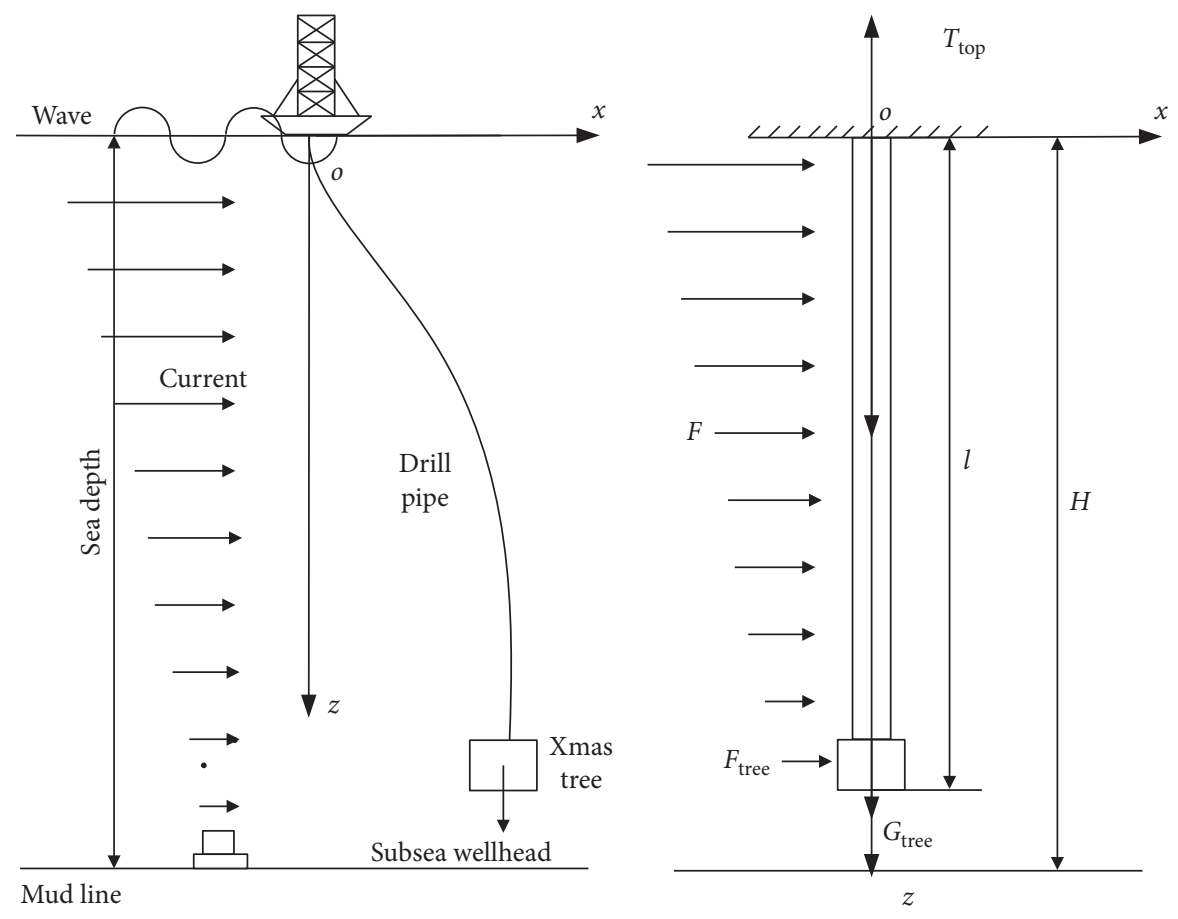

(a)

(b)

FIgURE 1: (a) Schematic diagram and (b) mechanical analysis model for the subsea Xmas tree installation process.

$$
\left.\begin{array}{l}
w=\frac{1}{4} \pi g\left(\rho_{\mathrm{s}}-\rho_{\mathrm{w}}\right)\left(D^{2}-d^{2}\right), \\
T(z)=m_{\mathrm{B}} g+\int_{z}^{l} w \mathrm{~d} z,
\end{array}\right\}
$$

where $z$ is the distance from the section to the top of the pipe; $w(z)$ is the net weight of the pipe (per unit length); $m_{\mathrm{B}} g$ is the suspend weight at the pipe bottom, i.e., the combined weight of the tree and installation tool; $\rho_{\mathrm{s}}$ is the density of the pipe; $\rho_{\mathrm{w}}$ is the density of seawater; and $D$ and $d$ are the outer and inner diameters of the pipe, respectively.

The effective mass of the pipe per unit length includes the pipe body, internal fluid, and added mass. $m_{\mathrm{e}}(z)$ is calculated by

$$
\left.\begin{array}{l}
m_{\mathrm{e}}(z)=m_{\mathrm{p}}+m_{\mathrm{f}}+m_{\mathrm{a}}, \\
m_{\mathrm{p}}=\frac{1}{4} \pi \rho_{\mathrm{s}}\left(D^{2}-d^{2}\right), \\
m_{\mathrm{f}}=\frac{1}{4} \pi \rho_{\mathrm{f}} d^{2}, \\
m_{\mathrm{a}}=\frac{1}{4} \pi C_{\mathrm{a}} \rho_{\mathrm{w}} D^{2},
\end{array}\right\}
$$

where $m_{\mathrm{p}}$ is the mass of the pipe; $m_{\mathrm{f}}$ is the mass of the internal fluid; $m_{\mathrm{a}}$ is the added mass; $C_{\mathrm{a}}$ is the added mass factor; and $\rho_{\mathrm{f}}$ is the density of the internal fluid. The internal and external fluids are both seawater with the same density because seawater can flow freely into the pipe from the bottom of the tree during the lowering process.

Equation (4) presents the boundary conditions of the pipe at $z=0$ and $z=l$ :

$$
\left.\begin{array}{l}
\left.x(z, t)\right|_{z=0}=0, \\
\left.\frac{\partial x(z, t)}{\partial z}\right|_{z=0}=0 \\
-\left.E(z) I(x) \frac{\partial^{3} x(z, t)}{\partial z^{3}}\right|_{z=l}+T(z) \frac{\partial x(z, t)}{\partial z}=-\left.m_{\mathrm{B}}(z) \frac{\partial^{2} x(z, t)}{\partial t^{2}}\right|_{z=l}, \\
\left.E(z) I(x) \frac{\partial^{2} x(z, t)}{\partial z^{2}}\right|_{z=l}=0 .
\end{array}\right\}
$$

In order to solve equation (1), the separation of variable method is used as follows:

$$
x(z, t)=\varphi(z) \gamma(t)
$$

where the lateral deflection of the pipe is expressed as the product of a spatial function $\varphi(z)$ and a temporal function $\gamma(t)$.

The governing equation of the pipe can be deduced by substituting equation (5) into equation (1) as follows:

$$
\begin{aligned}
& \frac{\partial^{2}}{\partial z^{2}}\left(E(z) I(z) \frac{\partial^{2} \varphi(z)}{\partial z^{2}}\right)-\frac{\partial}{\partial z}\left(T(z) \frac{\partial \varphi(z)}{\partial z}\right) \\
& \quad-m_{\mathrm{e}}(z) \omega^{2} \varphi(z)=0 .
\end{aligned}
$$


The boundary condition equations of the pipe can be converted into a new form by substituting equation (5) into equation (4) as follows:

$$
\begin{aligned}
& \left.\varphi(z)\right|_{z=0}=0 \\
& \left.\frac{\partial \varphi(z)}{\partial z}\right|_{z=0}=0 \\
& -\left.E(z) I(z) \frac{\partial^{3} \varphi(z)}{\partial z^{3}}\right|_{z=l}+T(z) \frac{\partial \varphi(z)}{\partial z}=-\left.m_{\mathrm{B}}(z) \omega^{2} \varphi(z)\right|_{z=l}, \\
& \left.E(z) I(z) \frac{\partial^{2} \varphi(z)}{\partial z^{2}}\right|_{z=l}=0 .
\end{aligned}
$$

2.2. Dimensionless Transformation. Two nondimensional parameters:

$$
\begin{gathered}
\bar{z}=\frac{z}{l}, \\
\bar{\varphi}=\frac{\varphi}{l} .
\end{gathered}
$$

Using a spectral representation [21], equation (6) can be written as follows:

$$
\begin{aligned}
& \frac{\partial^{2}}{\partial \bar{z}^{2}}\left(E(z) I(z) \frac{\partial^{2} \varphi(\bar{z})}{\partial \bar{z}^{2}}\right)-l^{2} \frac{\partial}{\partial \bar{z}}\left(T(z) \frac{\partial \varphi(\bar{z})}{\partial \bar{z}}\right) \\
& -m_{\mathrm{e}}(\bar{z}) \omega^{2} l^{4} \varphi(\bar{z})=0 .
\end{aligned}
$$

Both sides of equation (6) are then divided by $E(0) I(0)$ :

$$
\begin{aligned}
& \frac{\partial^{2}}{\partial \bar{z}^{2}}\left(\frac{E(z) I(z)}{E(0) I(0)} \frac{\partial^{2} \varphi(\bar{z})}{\partial \bar{z}^{2}}\right)-\frac{\partial}{\partial \bar{z}}\left(\frac{l^{2} T(z)}{E(0) I(0)} \frac{\partial \varphi(\bar{z})}{\partial \bar{z}}\right) \\
& -\frac{m_{\mathrm{e}}(\bar{z}) \omega^{2} l^{4}}{E(0) I(0)} \varphi(\bar{z})=0,
\end{aligned}
$$

where the following dimensionless quantities can be defined:

$$
\begin{aligned}
a(\bar{z}) & =\frac{E(z) I(z)}{E(0) I(0)}, \\
b(\bar{z}) & =\frac{l^{2} T(z)}{E(0) I(0)}, \\
q(\bar{z}) & =\frac{m_{\mathrm{e}}(\bar{z})}{m_{\mathrm{e}}(0)}, \\
\lambda^{4} & =\frac{m_{\mathrm{e}}(0) \omega^{2} l^{4}}{E(0) I(0)} .
\end{aligned}
$$

Equation (10) can be written as follows:

$$
\frac{\partial^{2}}{\partial \bar{z}^{2}}\left(a(\bar{z}) \frac{\partial^{2} \varphi(\bar{z})}{\partial \bar{z}^{2}}\right)-\frac{\partial}{\partial \bar{z}}\left(b(\bar{z}) \frac{\partial \varphi(\bar{z})}{\partial \bar{z}}\right)-q(\bar{z}) \lambda^{4} \varphi(\bar{z})=0 .
$$

The same dimensionless treatment method is used, and the nondimensional boundary conditions become

$$
\begin{aligned}
& \left.\varphi(\bar{z})\right|_{\bar{z}=0}=0, \\
& \left.\frac{\partial \varphi(\bar{z})}{\partial \bar{z}}\right|_{\bar{z}=0}=0, \\
& \left.a(\bar{z}) \frac{\partial^{3} \varphi(\bar{z})}{\partial \bar{z}^{3}}\right|_{\bar{z}=l}-b(\bar{z}) \frac{\partial \varphi(\bar{z})}{\partial \bar{z}}-\left.\zeta_{\mathrm{m}} \lambda^{2} \varphi(\bar{z})\right|_{\bar{z}=l}=0, \\
& \left.\frac{\partial^{2} \varphi(\bar{z})}{\partial \bar{z}^{2}}\right|_{\bar{z}=l}=0,
\end{aligned}
$$

where $\zeta_{\mathrm{m}}=m_{\mathrm{B}} / m_{\mathrm{e}}(0) l$.

2.3. Extracting the Frequencies and Mode Shapes by the DTM. The differential transformation of the $k$ th-order derivative of a function $\phi(z)$ is represented as follows:

$$
\Phi(k)=\frac{1}{k !}\left[\frac{\partial^{k} \varphi(\bar{z})}{\partial \bar{z}^{k}}\right] \mid \bar{z}=\bar{z}_{0}, \quad 0 \leq \bar{z} \leq 1,
$$

where $\Phi(k)$ is referred to as the $k$ th-order differential transformation (T-function) at the point $x=x_{0}, x_{0}=0$ is usually assumed for convenience but is not necessary. The inverse differential transformation can be written in the following form:

$$
\varphi(\bar{z})=\sum_{k}^{\infty}\left(\bar{z}-\bar{z}_{0}\right)^{k} \frac{1}{k !}\left[\frac{\partial^{k} \varphi(\bar{z})}{\partial \bar{z}^{k}}\right]=\sum_{k}^{\infty}\left(\bar{z}-\bar{z}_{0}\right)^{k} \Phi(k) .
$$

Equation (15) implies that the DTM is derived from Taylor series expansion of the function $\phi(z)$ at $z=z_{0}$.

The fundamental transformation rules [22] are listed in Table 1 .

Based on the differential transformation of equation (14) and the basic operations in Table 1, the governing equation in equation (12) can be converted into the following recursive equation:

$$
\begin{aligned}
& \sum_{r=0}^{k} A(k-r)(r+1)(r+2)(r+3)(r+4) \Phi(r+4) \\
& \quad+2 \sum_{r=0}^{k}(k-r+1) A(k-r+1)(r+1)(r+2)(r+3) \Phi(r+3) \\
& \quad+\sum_{r=0}^{k}(k-r+1)(k-r+2) A(k-r+2)(r+1)(r+2) \Phi(r+2) \\
& \quad-\sum_{r=0}^{k} B(k-r)(r+1)(r+2) \Phi(r+2) \\
& \quad-\sum_{r=0}^{k}(k-r+1) B(k-r+1)(r+1) \Phi(r+1) \\
& =\lambda^{4} \Phi(r) Q(k-r),
\end{aligned}
$$


TABLe 1: Basic operations for applications of differential transformation.

\begin{tabular}{lc}
\hline Original function $f(z)$ & Transformed function $F(k)$ \\
\hline$f(z)=\lambda g(z)$ & $F(k)=\lambda G(k)$ \\
$f(z)=g(z) \pm h(z)$ & $F(k)=G(x) \pm H(k)$ \\
$f(z)=g(z) h(z)$ & $F(k)=\sum_{r=0}^{k} G(r) \pm H(k-r)$ \\
$f(z)=g_{1}(z) g_{2}(z) \cdots g_{n-1}(z) g_{n}(z)$ & $F(k)=\sum_{k_{n-1}=0}^{k} \sum_{k_{n-2}=0}^{k_{n-1}} \cdots \sum_{k_{2}=0}^{k_{3}} \sum_{k_{1}=0}^{k_{2}} G_{1}\left(k_{1}\right) G_{2}\left(k_{2}-k_{1}\right) \cdots G_{n-1}\left(k_{n-1}-k_{n-2}\right) G_{n}\left(k_{n}-k_{n-1}\right)$ \\
$f(z)=\left(\mathrm{d}^{k} g(z)\right) / \mathrm{d} x^{k}$ & $F(k)=(k+1)(k+2) \cdots(k+i) G(k+i)$ \\
\hline
\end{tabular}

where $\Phi(k), A(k), B(k)$, and $Q(k)$ are the transformed functions of $\phi(z), a(z), b(z)$, and $q(z)$, respectively.
The transformed boundary condition equations can be deduced by substituting equation (15) into equation (13) as follows:

$$
\begin{aligned}
& \left.\sum_{k=0}^{\infty}\left(\bar{z}-\bar{z}_{0}\right)^{k} \Phi(k)\right|_{\bar{z}=0}=0 \\
& \left.\sum_{k=0}^{\infty} k\left(\bar{z}-\bar{z}_{0}\right)^{(k-1)} \Phi(k)\right|_{\bar{z}=0}=0 \\
& \left.a(\bar{z}) \sum_{k=0}^{\infty} k(k-1)(k-2)\left(\bar{z}-\bar{z}_{0}\right)^{(k-3)} \Phi(k)\right|_{\bar{z}=1}-\left.b(\bar{z}) \sum_{k=0}^{\infty} k\left(\bar{z}-\bar{z}_{0}\right)^{(k-1)} \Phi(k)\right|_{\bar{z}=1}+\left.\zeta_{\mathrm{m}} \lambda^{2} \sum_{k=0}^{\infty}\left(\bar{z}-\bar{z}_{0}\right)^{k} \Phi(k)\right|_{\bar{z}=1}=0, \\
& \left.\sum_{k=0}^{\infty} k(k-1)\left(\bar{z}-\bar{z}_{0}\right)^{(k-2)} \Phi(k)\right|_{\bar{z}=1}=0 .
\end{aligned}
$$

Considering that equation (16) is a recursive formula; suppose $\Phi(0)=\xi 1, \Phi(1)=\xi 2, \Phi(2)=\xi 3$, and $\Phi(3)=\xi 4$; therefore, $\Phi(\mathrm{k})$ can be represented by $\xi 1, \xi 2, \xi 3$, and $\xi 4$. Then, substitute these terms into the four boundary conditions of equation (17). A set of homogeneous equations of quaternion polynomials can be obtained, which can be assembled into a matrix equation of the following form:

$$
[A]_{4 \times 4}\left\{\xi_{1}, \xi_{2}, \xi_{3}, \xi_{4}\right\}_{1 \times 4}^{\mathrm{T}}=0,
$$

where $[A]$ is the coefficient matrix of equation (15). In order to ensure that equation (18) has nontrivial solutions, the determinant of matrix $[A]$ must be equal to zero, which will reveal an $n$ th-order polynomial about the eigenvalue $\lambda$. Thus, the eigenvalue $\lambda$ can be obtained by solving the polynomial and subsequently solving for the natural frequency of the pipe as follows:

$$
\omega=\frac{\lambda^{2}}{l^{2}} \sqrt{\frac{E I}{m_{\mathrm{e}}}} .
$$

The mode shapes of the pipe can be obtained once the values of $\lambda$ are found. By setting $\xi 1=1, \xi 2, \xi 3$, and $\xi 4$ can be determined by substituting $\lambda$ into equation (18). After obtaining $\xi 1 \sim \xi 4$, the $\Phi(k)$ can be generated by equation (16), which will allow the mode shape to be solved by the differential inverse transformation of equation (15), which can be subsequently normalized as follows [22]:

$$
\varphi(z)=\frac{\varphi(z)}{\int_{0}^{1}|\varphi(z)| \mathrm{d} z} .
$$

\section{Model Experiment}

3.1. Experiment Set. In order to verify whether the method can be used to calculate the frequency of the pipe when lowering a subsea Xmas tree, four drill pipe models of different sizes were made from stainless steel (SUS 304), and their properties are listed in Table 2. The top end of the model was fixed on the bracket and the bottom part was set to be free as a lumped mass, as shown in Figure 2. The experiment was carried out in a tank $(1500 \mathrm{~mm}$ long $\times 800 \mathrm{~mm}$ wide $\times 950 \mathrm{~mm}$ deep) which was designed and constructed for water research. Water flowed freely in the model, and we assumed that the entrained water in the simulation scheme vibrate with the model.

Two kinds of sensors were used to test the natural frequency of model: the piezoelectric acceleration (PA) sensor and the fiber Bragg grating (FBG) sensor. As shown in Figure 2, the optical sensing interrogator, which has a full spectrum at $5 \mathrm{kHz}$ with $80 \mathrm{~nm}$ and a wavelength accuracy of $2 \mathrm{pm} / 3 \mathrm{pm}$, was used to detect optical signals from the FBG sensor. The PA sensor signal was collected and processed by a DH5902N data acquisition and analysis system with a $2 \mathrm{kHz}$ sampling rate.

Seven locations were selected to place the PA sensors and FBG sensors; their arrangements are shown in Figure 3. " $x_{1}$ " was used to capture the $x$-axis vibration, and " $y_{2}$ " was used to capture the $y$-axis vibration.

3.2. Test Content. In this paper, we carried out oscillating experiments in still water. The values of the diameter $D$ and 
TABLE 2: Characteristics of the pipe model.

\begin{tabular}{lcccc}
\hline Property & & & Value & \\
& Model 1 & Model 2 & Model 3 & 0.9 \\
Length of the pipe $(l) \mathrm{m}$ & 0.9 & 1.5 & 40 & 1.5 \\
Outside diameter $(D) \mathrm{mm}$ & 10 & 10 & 2.3 & 40 \\
Thickness of pipe $(\delta) \mathrm{mm}$ & 1 & 1 & 7930 & 2.3 \\
Density of drill pipe $(\rho s) \mathrm{kg} / \mathrm{m}^{3}$ & 7930 & 7930 & 206 & 2030 \\
Elastic modulus of steel $(E) \mathrm{GPa}$ & 206 & 1 & 1 & 1 \\
Add mass coefficient $\left(C_{\mathrm{a}}\right)$ & 1 & $0 \sim 0.55$ & $0 \sim 5$ & $0 \sim 5$ \\
Bottom mass of model $\left(W_{\mathrm{B}}\right) \mathrm{kg}$ & $0 \sim 0.55$ & & 206 \\
\hline
\end{tabular}

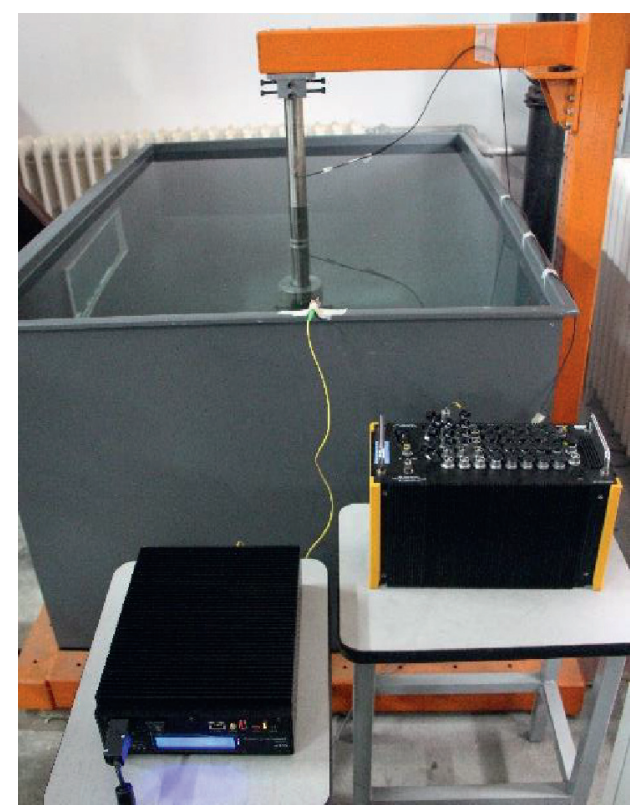

(a)

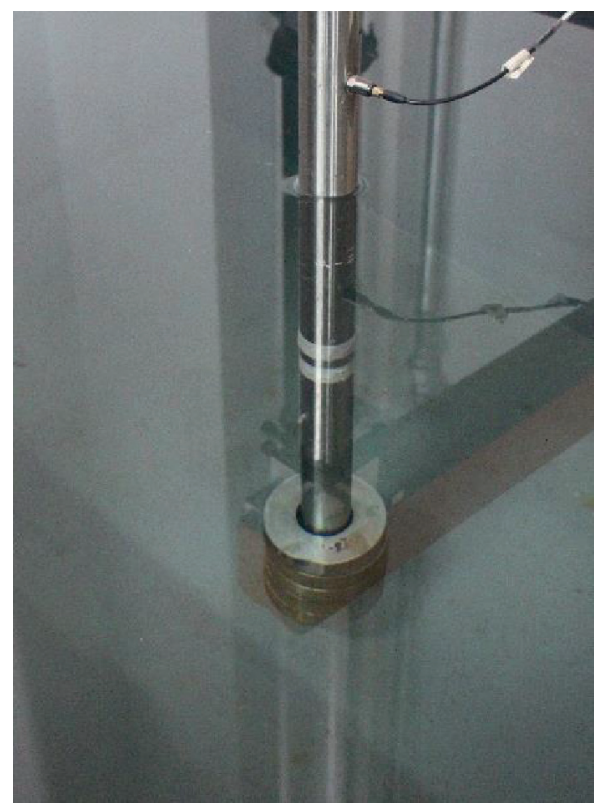

(b)

Figure 2: Riser pipe model and its part. (a) Pipe model and measuring devices and (b) part of the pipe model.

the lumped mass $m$ used in experiment for all test cases are listed in Table 3.

3.3. DTM. Since the pipe model adopted in this paper is uniform in the whole length direction, the governing equation of equation (10) can be simplified as follows:

$$
\frac{\mathrm{d}^{4} \varphi(\bar{z})}{\mathrm{d} \bar{z}^{4}}-\frac{\mathrm{d}}{\mathrm{d} \bar{z}}\left((\alpha-\beta \bar{z}) \frac{\mathrm{d} \varphi(\bar{z})}{\mathrm{d} \bar{z}}\right)-\lambda^{4} \varphi(\bar{z})=0,
$$

where $\quad \alpha=\left(l^{2} / E I\right)\left(w l+m_{\mathrm{B}} g\right), \quad \beta=w l^{3} / E I, \quad$ and $\lambda^{4}=m_{\mathrm{e}} \omega^{2} l^{4} / E I$. Equation (16) can be correspondingly converted into the following recursive equation using the DTM:

$$
\begin{aligned}
\Phi(k+4)= & \frac{\left(\mu+v x_{0}\right) \Phi(k+2)}{(k+3)(k+4)}+\frac{v(k+1) \Phi(k+1)}{(k+2)(k+3)(k+4)} \\
& +\frac{\lambda^{4} \Phi(k)}{(k+1)(k+2)(k+3)(k+4)} .
\end{aligned}
$$

3.4. Experimental Results. Table 4 shows the error in the prediction of the natural frequencies of the model pipe, where the error is defined as the percentage of the ratio of the absolute difference between experimental values and theoretical calculating values. Error1 is the error between value measured by the PA sensor and the theoretical calculating value; the maximum error occurs at the fourth frequency of Exp20, and the error is $15.53 \%$, while the minimum error is $0.04 \%$, which occurs at the fourth frequency of Exp10, and the average error is less than 5\%. Error2 represents the error between the value from the FBG sensor and the theoretical calculating value; the maximum error is $8.93 \%$, which occurs at the fifth frequency of Exp22, while the smallest error is $0.05 \%$ for the fifth frequency of Exp21, and the mean error is $2.8 \%$. Error3 is the error between the two experimental sensors, and the mean error is $3.09 \%$. The frequency obtained using the DTM is acceptable enough for design purposes because the mean error is generally less than $5 \%$; thus, the frequency of the pipe when lowering a subsea Xmas tree can be determined using the equations and technique proposed in this paper. 


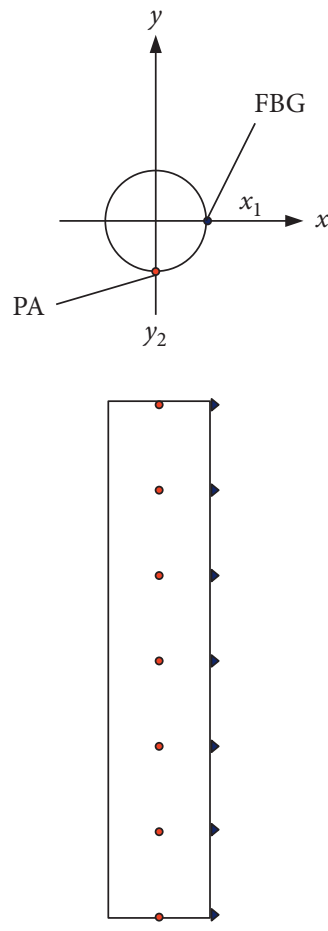

(a)

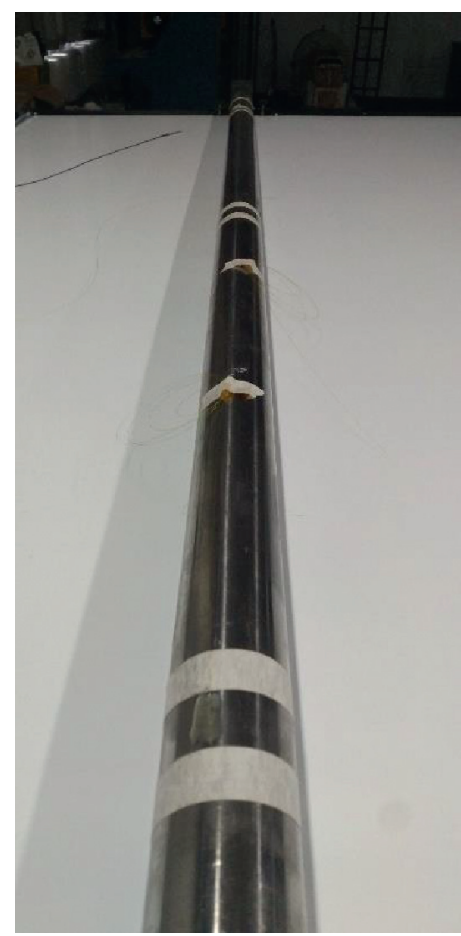

(b)

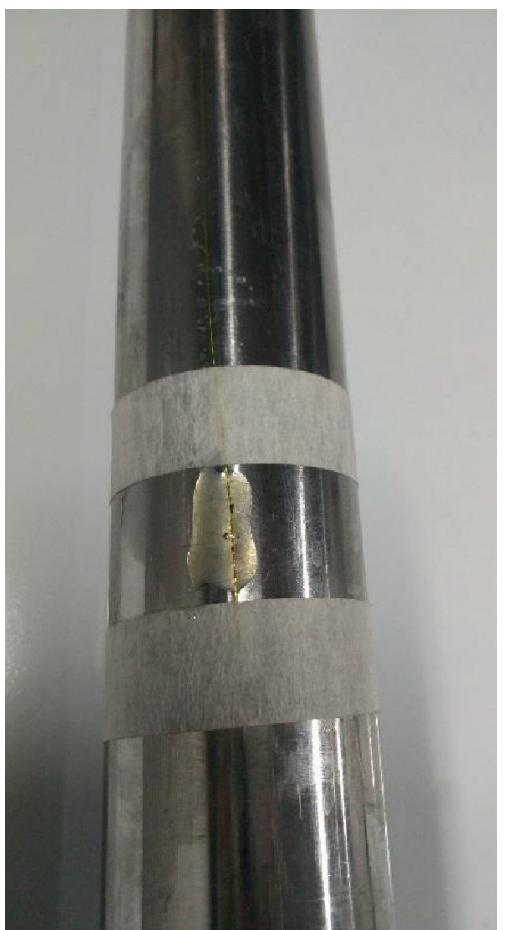

(c)

FIGURE 3: Schematic view of the pipe model and measuring points in experiment: (a) a schematic diagram of sensors, (b) a picture of pipe model with sensors, and (c) sensors.

TABLE 3: Experimental conditions.

\begin{tabular}{|c|c|c|c|c|c|c|c|c|}
\hline & \multirow{2}{*}{ The diameter $D(\mathrm{~mm})$} & \multirow{2}{*}{ Pipe length $L(\mathrm{~mm})$} & \multicolumn{6}{|c|}{ The lumped mass: $m(\mathrm{~g})$} \\
\hline & & & 0 & 103 & 206 & 309 & 412 & 515 \\
\hline Model 1 & 10 & 900 & Exp1 & Exp2 & Exp3 & Exp4 & Exp5 & Exp6 \\
\hline \multirow[t]{3}{*}{ Model 2} & 10 & 1500 & Exp7 & Exp8 & Exp9 & Exp10 & Exp11 & Exp12 \\
\hline & & & \multicolumn{6}{|c|}{ The lumped mass: $m(\mathrm{~g})$} \\
\hline & ine alameter $D(\mathrm{~mm})$ & Pipe length $L(\mathrm{~mm})$ & 0 & 1155 & 2097 & 3032 & 3972 & 4912 \\
\hline Model 3 & 40 & 900 & Exp13 & Exp14 & Exp15 & Exp16 & Exp17 & Exp18 \\
\hline Model 4 & 40 & 1500 & Exp19 & Exp20 & Exp21 & Exp22 & Exp23 & Exp24 \\
\hline
\end{tabular}

Figure 4 shows a plot of the experimentally measured natural frequencies of the model pipe in still water in comparison with the natural frequencies predicted by the DTM using the equations developed in this paper. Results of experimental tests prove that the theoretical calculating values match well with the experimental measuring values.

By comparing the curve of Exp1 with that of Exp7 or by comparing the curve of Exp13 with that of Exp19 in Figure 5, it can be observed that as the length of the pipe model increases, the natural frequencies of each order decreases, and thus, it can be inferred that the natural frequency of the system decreases gradually during the process of lowering the pipe. At the same time, by comparing the curve of Exp1 with that of Exp13 or by comparing the curve of Exp7 with that of Exp19, it can be seen that the specification of the pipe is an important factor affecting the natural frequency of the system. In the case of the same length, the larger the diameter of the pipe is, the higher the natural frequency of each order will be.

The effect of the lumped mass at the bottom of the pipe on the natural frequency of the model pipe 1 is plotted in Figure 6. It is obvious from Figure 6 that the natural frequency of the pipe model decreases with increasing bottom weight, and the results obtained by the two experimental sensors are consistent with the theoretical calculation. Therefore, in an actual project, the weight of the Xmas tree has a significant impact on the frequency of the whole lowering system.

Figure $7(a)-7(f)$ show the mode shapes of the pipe model; these modes are obtained by the DTM and FBG sensor, respectively. It can be seen that the first five mode shapes obtained by the theoretical method and experimental sensor are basically coincident. The mode shapes of the pipe can be determined using the equations and technique proposed in this paper. However, the amplitudes of the 
TABLE 4: Error of predicted natural frequencies in experimental cases.

\begin{tabular}{|c|c|c|c|c|c|c|c|}
\hline Case & Natural frequency & Theoretical value & $\mathrm{PA}$ & FBG & Error1 (\%) & Error2 (\%) & Error3 (\%) \\
\hline \multirow{6}{*}{ Exp1 } & 1 st & 10.5147 & 10.7863 & 10.3401 & 2.58 & 1.66 & 4.14 \\
\hline & 2nd & 65.8235 & 60.4248 & 63.2812 & 8.20 & 3.86 & 4.73 \\
\hline & $3 r d$ & 184.2873 & 174.5605 & 176.1025 & 5.28 & 4.44 & 0.88 \\
\hline & 4 th & 361.1188 & 345.4591 & 345.3308 & 4.34 & 4.37 & 0.04 \\
\hline & 5 th & 596.9475 & 562.7441 & 580.5326 & 5.73 & 2.75 & 3.16 \\
\hline & 6th & 891.7300 & 825.1953 & 825.3219 & 7.46 & 7.45 & 0.02 \\
\hline \multirow{6}{*}{ Exp2 } & 1 st & 6.5076 & 7.3243 & 6.2983 & 12.55 & 3.22 & 14.01 \\
\hline & 2nd & 51.3432 & 48.8281 & 50.5211 & 4.90 & 1.60 & 3.47 \\
\hline & $3 r d$ & 155.5492 & 151.3672 & 153.6025 & 2.69 & 1.25 & 1.48 \\
\hline & 4 th & 318.0149 & 313.1104 & 312.9178 & 1.54 & 1.60 & 0.06 \\
\hline & 5 th & 539.2983 & 520.6299 & 520.6002 & 3.46 & 3.47 & 0.01 \\
\hline & 6 th & 819.4665 & 800.2637 & 810.2438 & 2.34 & 1.13 & 1.25 \\
\hline \multirow{6}{*}{ Exp3 } & $1 \mathrm{st}$ & 5.1823 & 5.4145 & 5.0371 & 4.48 & 2.80 & 6.97 \\
\hline & 2 nd & 49.1996 & 47.6074 & 47.5933 & 3.24 & 3.26 & 0.03 \\
\hline & $3 r d$ & 152.8061 & 150.7568 & 152.4119 & 1.34 & 0.26 & 1.10 \\
\hline & 4 th & 315.0362 & 310.3311 & 311.5492 & 1.49 & 1.11 & 0.39 \\
\hline & 5 th & 536.1817 & 515.8887 & 517.5979 & 3.78 & 3.47 & 0.33 \\
\hline & 6 th & 816.2613 & 788.8086 & 797.3321 & 3.36 & 2.32 & 1.08 \\
\hline \multirow{6}{*}{ Exp4 } & $1 \mathrm{st}$ & 4.4392 & 4.8828 & 4.1414 & 9.99 & 6.71 & 15.18 \\
\hline & $2 \mathrm{nd}$ & 48.3092 & 47.6074 & 47.6291 & 1.45 & 1.41 & 0.05 \\
\hline & $3 r d$ & 151.7448 & 149.5361 & 150.2124 & 1.46 & 1.01 & 0.45 \\
\hline & 4 th & 313.9227 & 307.0068 & 310.4764 & 2.20 & 1.10 & 1.13 \\
\hline & 5 th & 535.0382 & 509.0332 & 516.1435 & 4.86 & 3.53 & 1.40 \\
\hline & 6 th & 815.0991 & 787.5117 & 793.8137 & 3.38 & 2.61 & 0.80 \\
\hline \multirow{6}{*}{ Exp5 } & $1 \mathrm{st}$ & 3.9487 & 3.8521 & 3.8828 & 2.45 & 1.67 & 0.80 \\
\hline & 2 nd & 47.8260 & 47.6074 & 47.4852 & 0.46 & 0.71 & 0.26 \\
\hline & $3 r d$ & 151.1870 & 147.0947 & 148.7914 & 2.71 & 1.58 & 1.15 \\
\hline & 4 th & 313.3460 & 296.6309 & 307.1457 & 5.33 & 1.98 & 3.54 \\
\hline & 5 th & 534.4506 & 490.957 & 515.0786 & 8.14 & 3.62 & 4.91 \\
\hline & 6 th & 814.5047 & 781.6836 & 789.8112 & 4.03 & 3.03 & 1.04 \\
\hline \multirow{6}{*}{ Exp6 } & $1 \mathrm{st}$ & 3.5945 & 3.6828 & 3.4392 & 2.46 & 4.32 & 6.61 \\
\hline & 2 nd & 47.5255 & 46.9971 & 46.9573 & 1.11 & 1.20 & 0.08 \\
\hline & $3 r d$ & 150.8466 & 144.8877 & 140.8317 & 3.95 & 6.64 & 2.80 \\
\hline & 4 th & 312.9971 & 294.8539 & 297.3333 & 5.80 & 5.00 & 0.84 \\
\hline & 5 th & 534.0966 & 487.3223 & 513.5267 & 8.76 & 3.85 & 5.38 \\
\hline & 6th & 814.1477 & 779.2041 & 782.8726 & 4.29 & 3.84 & 0.47 \\
\hline \multirow{6}{*}{ Exp7 } & 1 st & 3.6311 & 3.9196 & 3.7399 & 7.94 & 3.00 & 4.58 \\
\hline & 2nd & 22.6353 & 24.4731 & 22.8863 & 8.12 & 1.11 & 6.48 \\
\hline & $3 r d$ & 63.3445 & 66.7916 & 61.7196 & 5.44 & 2.57 & 7.59 \\
\hline & 4 th & 124.1114 & 118.3987 & 120.8129 & 4.60 & 2.66 & 2.04 \\
\hline & 5 th & 205.1518 & 192.9841 & 197.6397 & 5.93 & 3.66 & 2.41 \\
\hline & 6th & 306.4508 & 281.2845 & 300.1003 & 8.21 & 2.07 & 6.69 \\
\hline \multirow{6}{*}{ Exp8 } & $1 \mathrm{st}$ & 2.6204 & 2.8489 & 2.7537 & 8.72 & 5.09 & 3.34 \\
\hline & 2 nd & 18.4668 & 19.3654 & 18.2873 & 4.87 & 0.97 & 5.57 \\
\hline & $3 r d$ & 54.6145 & 60.4631 & 57.3336 & 10.71 & 4.98 & 5.18 \\
\hline & 4 th & 110.6133 & 116.6287 & 112.7168 & 5.44 & 1.90 & 3.35 \\
\hline & 5 th & 186.7600 & 192.7039 & 189.0539 & 3.18 & 1.23 & 1.89 \\
\hline & 6 th & 283.1069 & 270.4674 & 274.4444 & 4.46 & 3.06 & 1.47 \\
\hline \multirow{6}{*}{ Exp9 } & $1 \mathrm{st}$ & 2.1833 & 2.3416 & 2.2396 & 7.25 & 2.58 & 4.36 \\
\hline & 2nd & 17.5189 & 18.8431 & 18.0539 & 7.56 & 3.05 & 4.19 \\
\hline & $3 r d$ & 53.2767 & 57.9743 & 55.8113 & 8.82 & 4.76 & 3.73 \\
\hline & 4 th & 109.0850 & 112.8 & 110.3336 & 3.41 & 1.14 & 2.19 \\
\hline & 5 th & 185.1139 & 189.7431 & 185.6987 & 2.50 & 0.32 & 2.13 \\
\hline & 6 th & 281.3824 & 269.1264 & 273.1249 & 4.36 & 2.93 & 1.49 \\
\hline
\end{tabular}


TABle 4: Continued.

\begin{tabular}{|c|c|c|c|c|c|c|c|}
\hline Case & Natural frequency & Theoretical value & $\mathrm{PA}$ & FBG & Error1 (\%) & Error2 (\%) & Error3 (\%) \\
\hline \multirow{6}{*}{ Exp10 } & 1 st & 1.9161 & 2.1341 & 2.0223 & 11.38 & 5.54 & 5.24 \\
\hline & 2nd & 17.0886 & 16.4631 & 17.2574 & 3.66 & 0.99 & 4.82 \\
\hline & $3 \mathrm{rd}$ & 52.7259 & 54.7598 & 53.7434 & 3.86 & 1.93 & 1.86 \\
\hline & 4 th & 108.4875 & 108.4394 & 109.2253 & 0.04 & 0.68 & 0.72 \\
\hline & 5 th & 184.4890 & 183.3648 & 183.5464 & 0.61 & 0.51 & 0.10 \\
\hline & 6 th & 280.7400 & 265.153 & 265.3254 & 5.55 & 5.49 & 0.07 \\
\hline \multirow{6}{*}{ Exp11 } & 1st & 1.7319 & 1.8821 & 1.7746 & 8.67 & 2.46 & 5.71 \\
\hline & 2 nd & 16.8468 & 16.1428 & 16.3394 & 4.18 & 3.01 & 1.22 \\
\hline & $3 r d$ & 52.4307 & 51.3689 & 51.8531 & 2.03 & 1.10 & 0.94 \\
\hline & 4 th & 108.1746 & 106.2254 & 107.1038 & 1.80 & 0.99 & 0.83 \\
\hline & 5 th & 184.1660 & 179.6413 & 177.6599 & 2.46 & 3.53 & 1.10 \\
\hline & 6 th & 280.4105 & 261.2791 & 260.7397 & 6.82 & 7.01 & 0.21 \\
\hline \multirow{6}{*}{ Exp12 } & 1 st & 1.5955 & 1.7325 & 1.7365 & 8.58 & 8.83 & 0.23 \\
\hline & 2nd & 16.6945 & 15.9542 & 15.9987 & 4.43 & 4.17 & 0.28 \\
\hline & $3 r d$ & 52.2501 & 49.254 & 48.4355 & 5.73 & 7.30 & 1.66 \\
\hline & 4 th & 107.9857 & 103.3634 & 105.3333 & 4.28 & 2.46 & 1.91 \\
\hline & 5 th & 183.9724 & 174.9213 & 176.5189 & 4.92 & 4.05 & 0.91 \\
\hline & 6th & 280.2139 & 254.3864 & 259.2547 & 9.22 & 7.48 & 1.91 \\
\hline \multirow{6}{*}{ Exp13 } & 1 st & 36.8698 & 34.4861 & $6.47 \%$ & 3.05 & 3.65 & 6.47 \\
\hline & $2 \mathrm{nd}$ & 231.0448 & 223.3359 & $3.34 \%$ & 0.50 & 2.93 & 3.34 \\
\hline & $3 \mathrm{rd}$ & 646.9281 & 673.7881 & $4.15 \%$ & 0.60 & 3.41 & 4.15 \\
\hline & 4 th & 1267.7187 & 1307.829 & $3.16 \%$ & 3.38 & 0.21 & 3.16 \\
\hline & 5 th & 2095.6284 & 2345.238 & $11.91 \%$ & 8.86 & 2.72 & 11.91 \\
\hline & 6th & 3130.5047 & 3380.716 & $7.99 \%$ & 5.38 & 2.42 & 7.99 \\
\hline \multirow{6}{*}{ Exp14 } & $1 \mathrm{st}$ & 23.7641 & 25.9533 & 22.6144 & 9.21 & 4.84 & 12.87 \\
\hline & $2 \mathrm{nd}$ & 182.1634 & 192.5408 & 189.4824 & 5.70 & 4.02 & 1.59 \\
\hline & $3 \mathrm{rd}$ & 548.7162 & 520.1795 & 540.8744 & 5.20 & 1.43 & 3.98 \\
\hline & 4 th & 1119.4019 & 999.7836 & 1089.3244 & 10.69 & 2.69 & 8.96 \\
\hline & 5 th & 1896.4459 & 1785.127 & 1823.8248 & 5.87 & 3.83 & 2.17 \\
\hline & 6th & 2880.1461 & 2769.759 & 2898.0893 & 3.83 & 0.62 & 4.63 \\
\hline \multirow{6}{*}{ Exp15 } & $1 \mathrm{st}$ & 19.5296 & 20.2378 & 18.8513 & 3.63 & 3.47 & 6.85 \\
\hline & $2 \mathrm{nd}$ & 174.6356 & 187.4995 & 183.9104 & 7.37 & 5.31 & 1.91 \\
\hline & $3 \mathrm{rd}$ & 538.8244 & 513.7513 & 533.0132 & 4.65 & 1.08 & 3.75 \\
\hline & 4 th & 1108.5160 & 1174.466 & 1089.7347 & 5.95 & 1.69 & 7.21 \\
\hline & 5 th & 1884.9708 & 1773.479 & 1736.2437 & 5.91 & 7.89 & 2.10 \\
\hline & 6th & 2868.2890 & 2537.492 & 2727.3099 & 11.53 & 4.92 & 7.48 \\
\hline \multirow{6}{*}{ Exp16 } & $1 \mathrm{st}$ & 16.9820 & 15.713 & 16.4131 & 7.47 & 3.35 & 4.46 \\
\hline & $2 \mathrm{nd}$ & 171.1710 & 159.9923 & 170.0844 & 6.53 & 0.63 & 6.31 \\
\hline & $3 \mathrm{rd}$ & 534.5942 & 551.7963 & 547.2145 & 3.22 & 2.36 & 0.83 \\
\hline & 4 th & 1104.0262 & 1208.198 & 1137.1944 & 9.44 & 3.00 & 5.88 \\
\hline & 5 th & 1880.3318 & 1976.187 & 1901.003 & 5.10 & 1.10 & 3.80 \\
\hline & 6th & 2863.5560 & 2761.761 & 2844.7672 & 3.55 & 0.66 & 3.01 \\
\hline \multirow{6}{*}{ Exp17 } & 1 st & 15.2184 & 15.1349 & 15.2124 & 0.55 & 0.04 & 0.51 \\
\hline & $2 \mathrm{nd}$ & 169.1611 & 174.3981 & 177.1978 & 3.10 & 4.75 & 1.61 \\
\hline & $3 \mathrm{rd}$ & 532.2258 & 530.1284 & 546.2446 & 0.39 & 2.63 & 3.04 \\
\hline & 4 th & 1101.5536 & 1194.7641 & 1116.3345 & 8.46 & 1.34 & 6.56 \\
\hline & 5 th & 1877.7996 & 1966.9432 & 1894.1487 & 4.75 & 0.87 & 3.70 \\
\hline & 6th & 2860.9866 & 2733.9673 & 2819.6687 & 4.44 & 1.44 & 3.13 \\
\hline \multirow{6}{*}{ Exp18 } & $1 \mathrm{st}$ & 13.9106 & 14.9721 & 14.1121 & 7.63 & 1.45 & 5.74 \\
\hline & $2 \mathrm{nd}$ & 167.8552 & 170.9841 & 172.3347 & 1.86 & 2.67 & 0.79 \\
\hline & $3 \mathrm{rd}$ & 530.7195 & 526.1192 & 538.9401 & 0.87 & 1.55 & 2.44 \\
\hline & 4 th & 1099.9959 & 1181.791 & 1104.0022 & 7.44 & 0.36 & 6.58 \\
\hline & 5 th & 1876.2124 & 1951.764 & 1884.2546 & 4.03 & 0.43 & 3.46 \\
\hline & 6 th & 2859.3811 & 2710.762 & 2804.3463 & 5.20 & 1.92 & 3.45 \\
\hline
\end{tabular}


TABle 4: Continued.

\begin{tabular}{|c|c|c|c|c|c|c|c|}
\hline Case & Natural frequency & Theoretical value & $\mathrm{PA}$ & FBG & Error1 (\%) & Error2 (\%) & Error3 (\%) \\
\hline \multirow{6}{*}{ Exp19 } & $1 \mathrm{st}$ & 12.6734 & 13.2563 & 12.3225 & 4.60 & 2.77 & 7.04 \\
\hline & $2 \mathrm{nd}$ & 79.3990 & 73.7568 & 78.4572 & 7.11 & 1.19 & 6.37 \\
\hline & $3 \mathrm{rd}$ & 222.3127 & 220.3311 & 224.6267 & 0.89 & 1.04 & 1.95 \\
\hline & 4 th & 435.6404 & 470.4668 & 452.6511 & 7.99 & 3.90 & 3.79 \\
\hline & 5 th & 720.1421 & 802.6058 & 769.3038 & 11.45 & 6.83 & 4.15 \\
\hline & 6th & 1075.7656 & 975.1812 & 1002.0375 & 9.35 & 6.85 & 2.75 \\
\hline \multirow{6}{*}{ Exp20 } & $1 \mathrm{st}$ & 9.3936 & 10.0974 & 9.8236 & 7.49 & 4.58 & 2.71 \\
\hline & 2nd & 65.5353 & 66.8899 & 66.7954 & 2.07 & 1.92 & 0.14 \\
\hline & $3 \mathrm{rd}$ & 192.8674 & 207.4506 & 198.1269 & 7.56 & 2.73 & 4.49 \\
\hline & 4th & 389.6997 & 450.232 & 420.3284 & 15.53 & 7.86 & 6.64 \\
\hline & 5 th & 657.1804 & 600.2085 & 650.7065 & 8.67 & 0.99 & 8.41 \\
\hline & 6th & 995.5286 & 1063.786 & 987.8547 & 6.86 & 0.77 & 7.14 \\
\hline \multirow{6}{*}{ Exp21 } & 1 st & 8.0243 & 7.7562 & 7.7034 & 3.34 & 4.00 & 0.68 \\
\hline & $2 \mathrm{nd}$ & 62.2993 & 58.189 & 60.8146 & 6.60 & 2.38 & 4.51 \\
\hline & $3 r d$ & 188.1462 & 200.0332 & 192.4503 & 6.32 & 2.29 & 3.79 \\
\hline & 4 th & 384.2031 & 381.5346 & 390.6624 & 0.69 & 1.68 & 2.39 \\
\hline & 5 th & 651.1935 & 644.4566 & 650.8563 & 1.03 & 0.05 & 0.99 \\
\hline & 6th & 989.2098 & 1002.723 & 990.5333 & 1.37 & 0.13 & 1.22 \\
\hline \multirow{6}{*}{ Exp22 } & $1 \mathrm{st}$ & 7.1245 & 6.8512 & 7.3369 & 3.84 & 2.98 & 7.09 \\
\hline & 2 nd & 60.6575 & 58.2123 & 57.8555 & 4.03 & 4.62 & 0.61 \\
\hline & $3 \mathrm{rd}$ & 185.9753 & 195.3257 & 189.6279 & 5.03 & 1.96 & 2.92 \\
\hline & 4 th & 381.8073 & 400.4822 & 395.1465 & 4.89 & 3.49 & 1.33 \\
\hline & 5 th & 648.6642 & 710.3375 & 706.5805 & 9.51 & 8.93 & 0.53 \\
\hline & 6th & 986.5939 & 1023.985 & 992.3503 & 3.79 & 0.58 & 3.09 \\
\hline \multirow{6}{*}{ Exp23 } & $1 \mathrm{st}$ & 6.4695 & 6.3356 & 6.4365 & 2.07 & 0.51 & 1.59 \\
\hline & $2 \mathrm{nd}$ & 59.6564 & 57.3487 & 57.0213 & 3.87 & 4.42 & 0.57 \\
\hline & $3 \mathrm{rd}$ & 184.7180 & 188.2234 & 185.34623 & 1.90 & 0.34 & 1.53 \\
\hline & 4 th & 380.4551 & 394.8947 & 388.1113 & 3.80 & 2.01 & 1.72 \\
\hline & 5 th & 647.2570 & 690.7536 & 660.2769 & 6.72 & 2.01 & 4.41 \\
\hline & 6th & 985.1517 & 1000.325 & 980.7383 & 1.54 & 0.45 & 1.96 \\
\hline \multirow{6}{*}{ Exp24 } & 1 st & 5.9677 & 6.2872 & 6.1012 & 5.35 & 2.24 & 2.96 \\
\hline & 2 nd & 58.9858 & 60.7298 & 56.3343 & 2.96 & 4.50 & 7.24 \\
\hline & $3 \mathrm{rd}$ & 183.9026 & 188.9128 & 180.3843 & 2.72 & 1.91 & 4.51 \\
\hline & 4 th & 379.5914 & 380.9412 & 377.5567 & 0.36 & 0.54 & 0.89 \\
\hline & 5 th & 646.3656 & 660.9734 & 652.2794 & 2.26 & 0.91 & 1.32 \\
\hline & 6th & 984.2429 & 991.5867 & 980.3444 & 0.75 & 0.40 & 1.13 \\
\hline
\end{tabular}

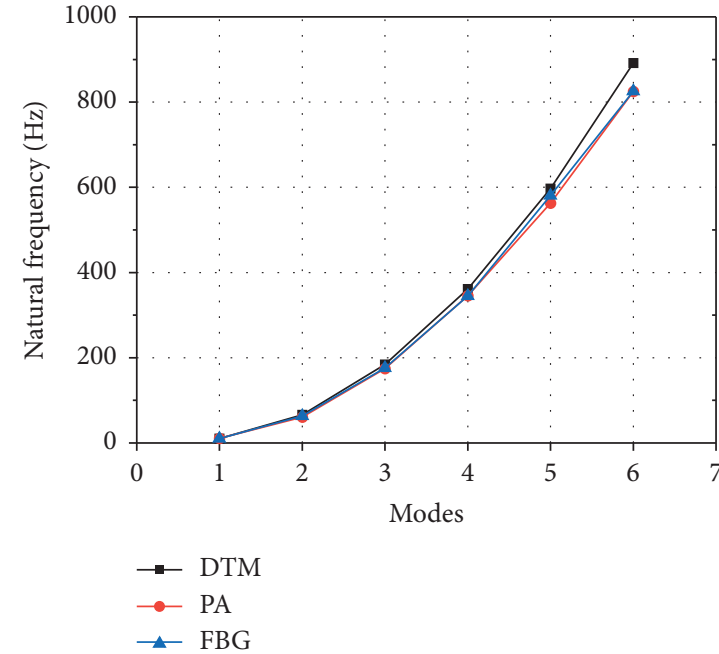

(a)

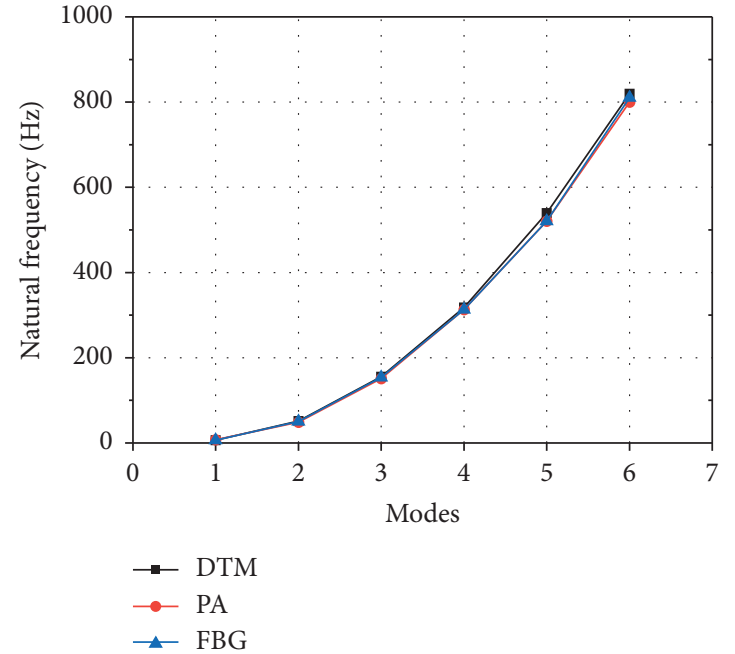

(b)

Figure 4: Continued. 

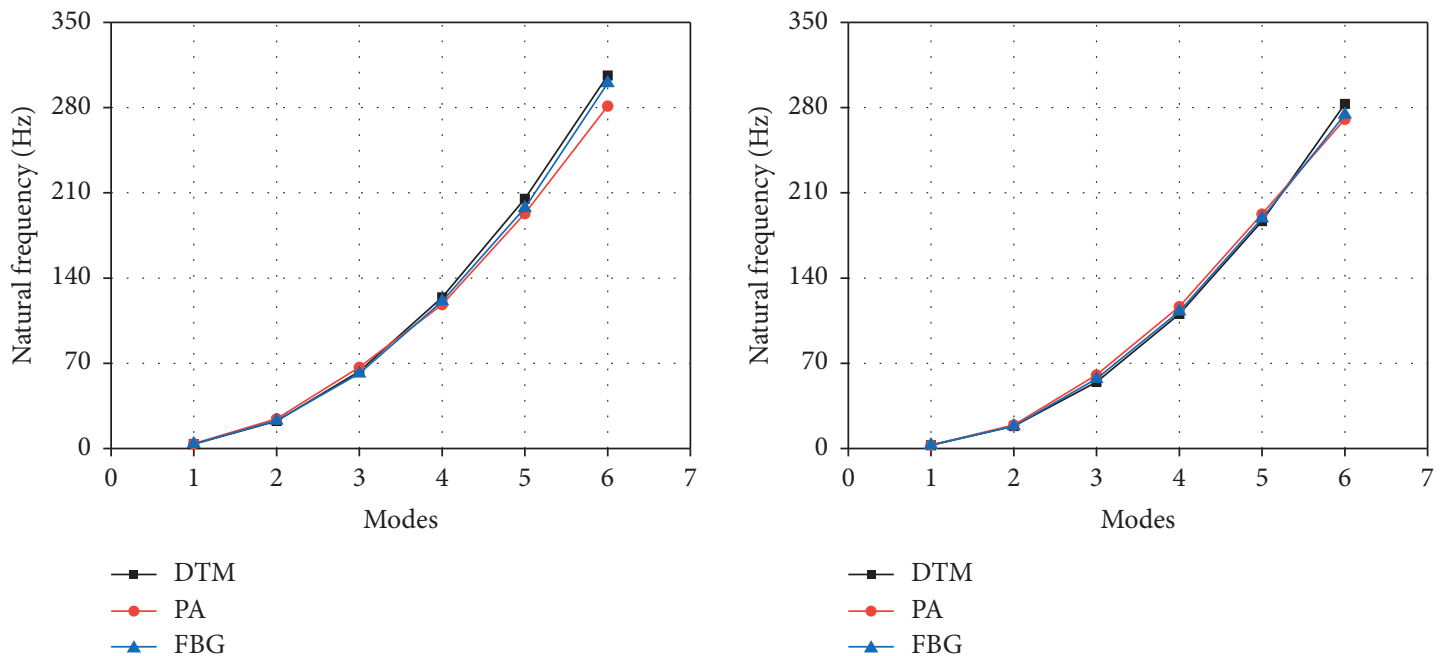

(c)

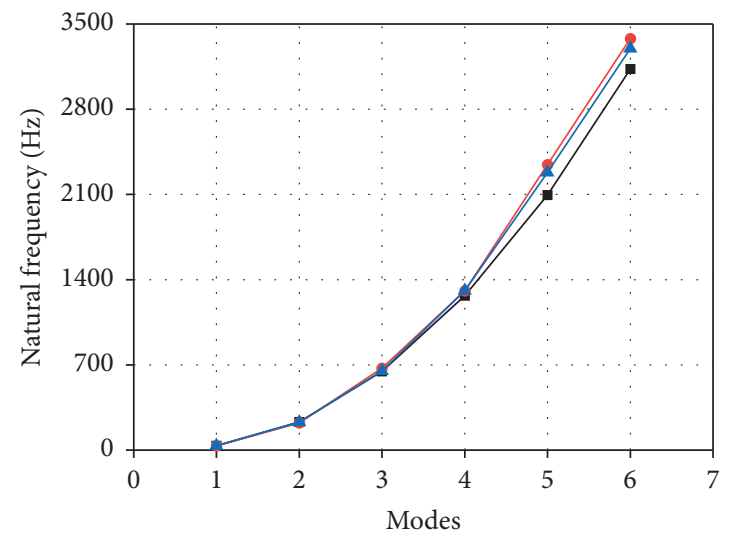

(d)

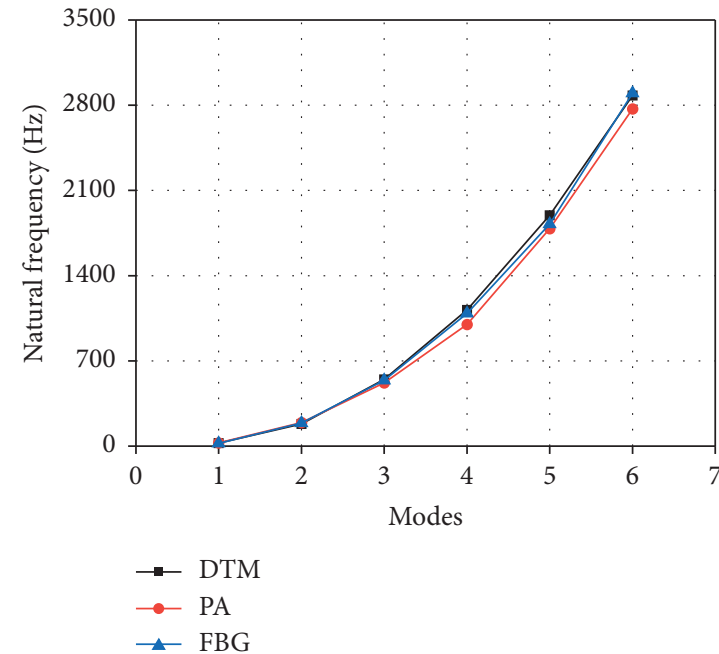

(e)

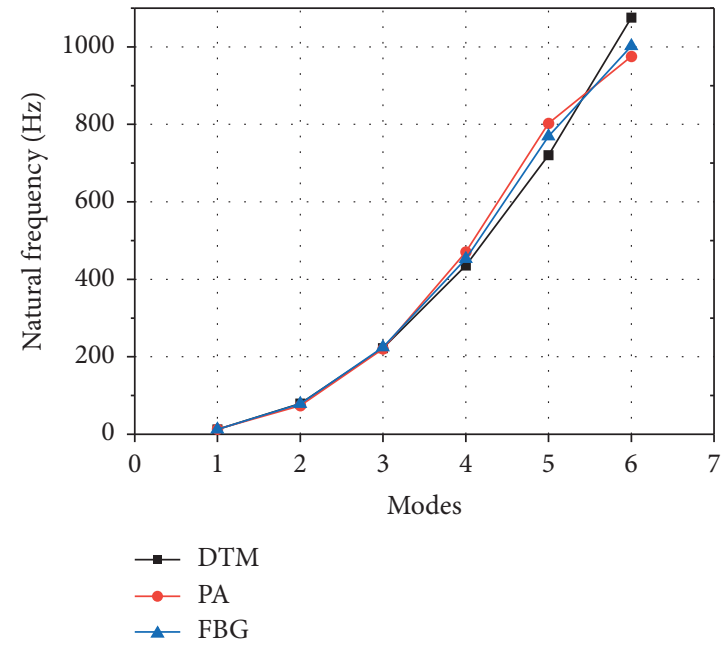

(g)

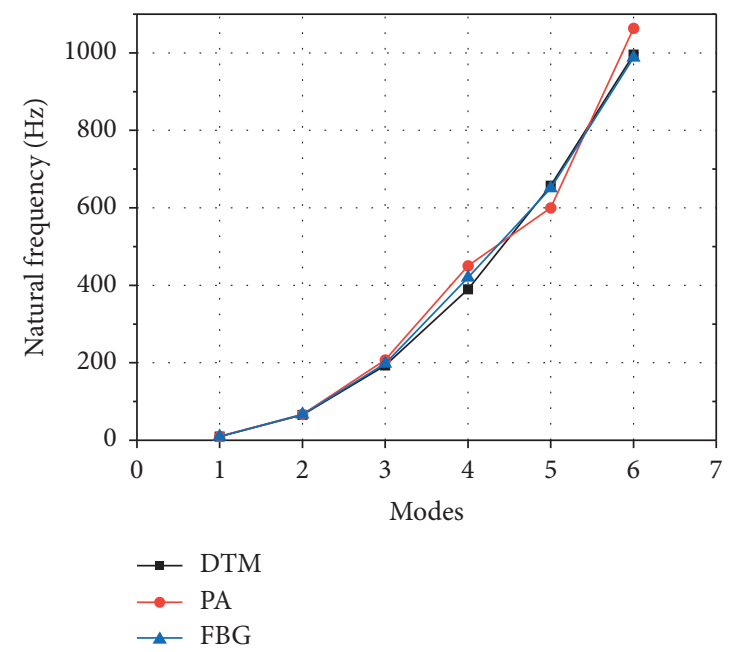

(h)

FIGURE 4: The frequencies of pipes in different methods: (a) model pipe 1 in Exp1, (b) model pipe 1 in Exp2, (c) model pipe 2 in Exp7, (d) model pipe 2 in Exp8, (e) model pipe 3 in Exp13, (f) model pipe 3 in Exp14, (g) model pipe 4 in Exp19, and (h) model pipe 4 in Exp20. 


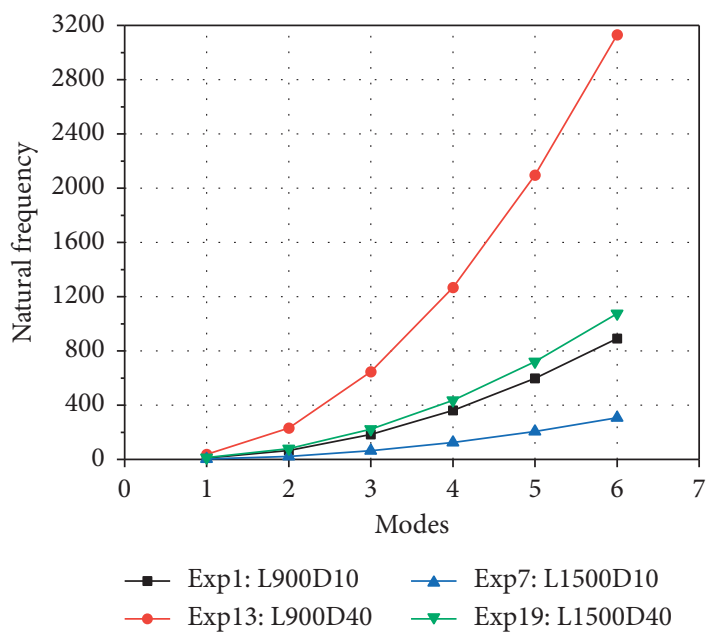

FIGURE 5: Comparisons of natural frequencies of the model pipe.

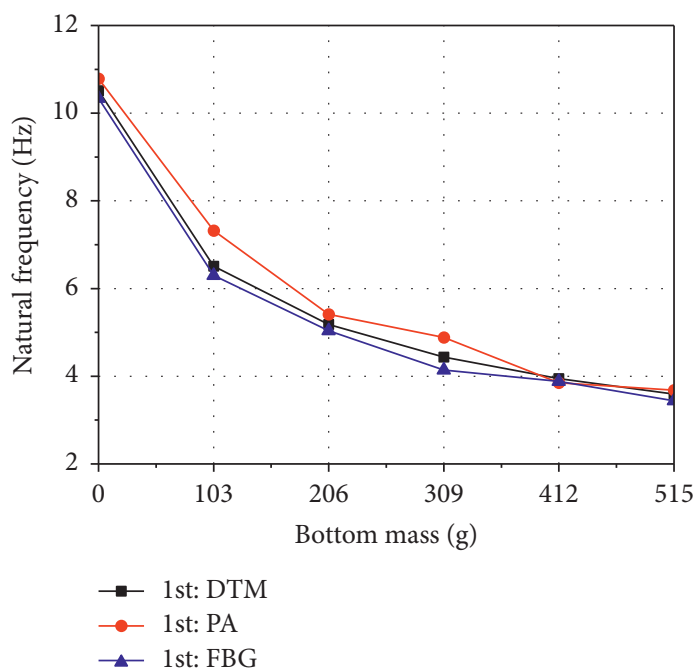

(a)

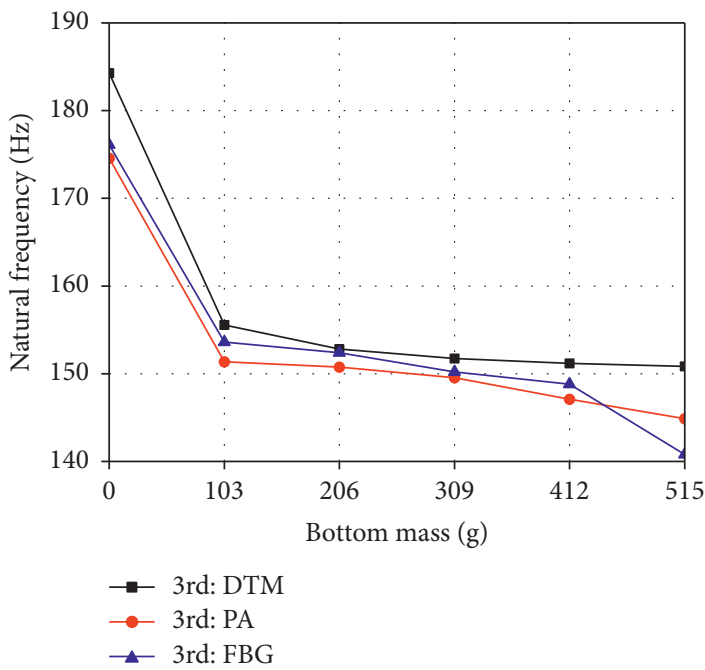

(c)

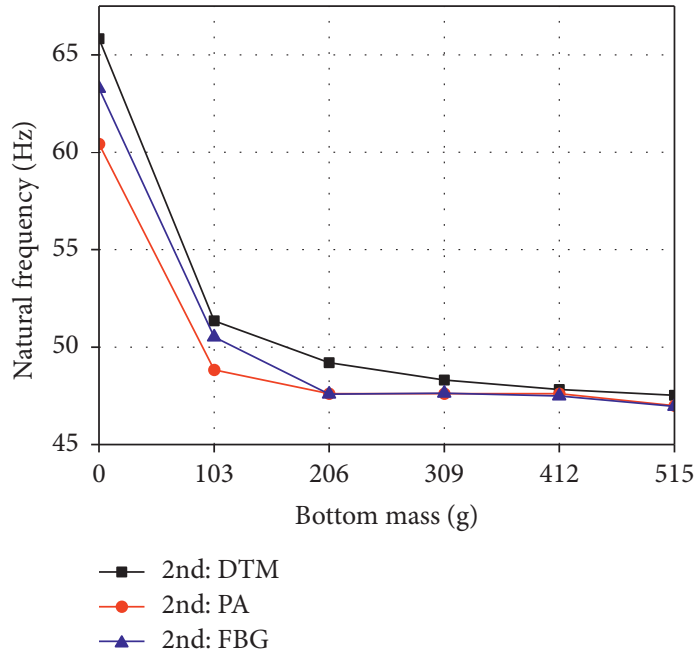

(b)

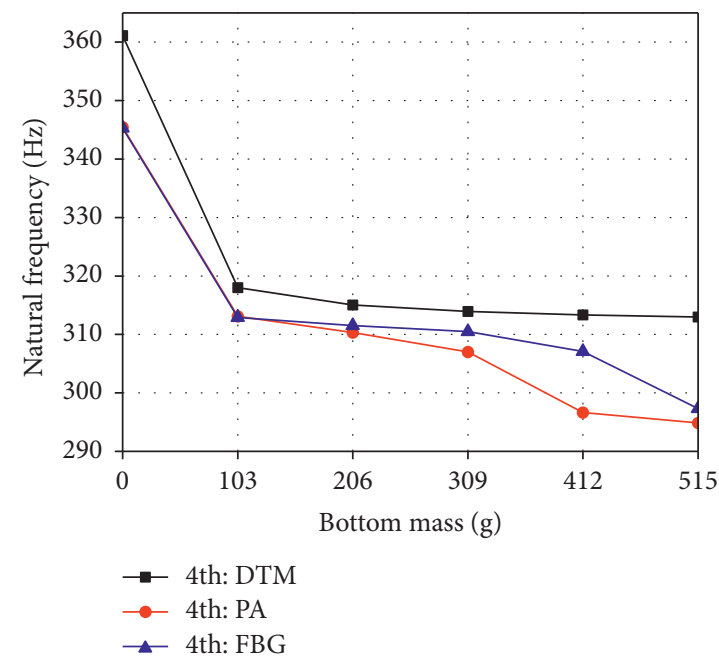

(d)

Figure 6: Natural frequencies of the model pipe 1 with a lumped mass: (a) first mode, (b) second mode, (c) third mode, and (d) fourth mode. 


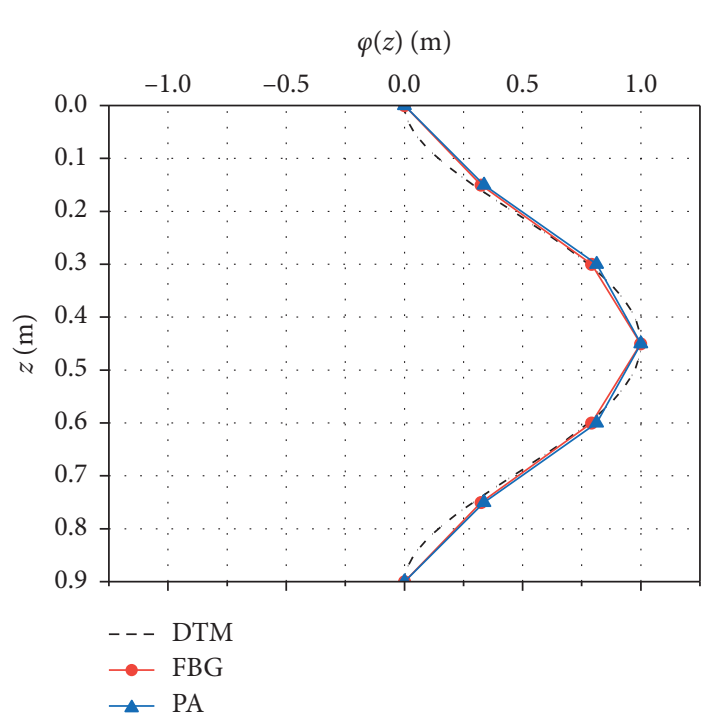

(a)

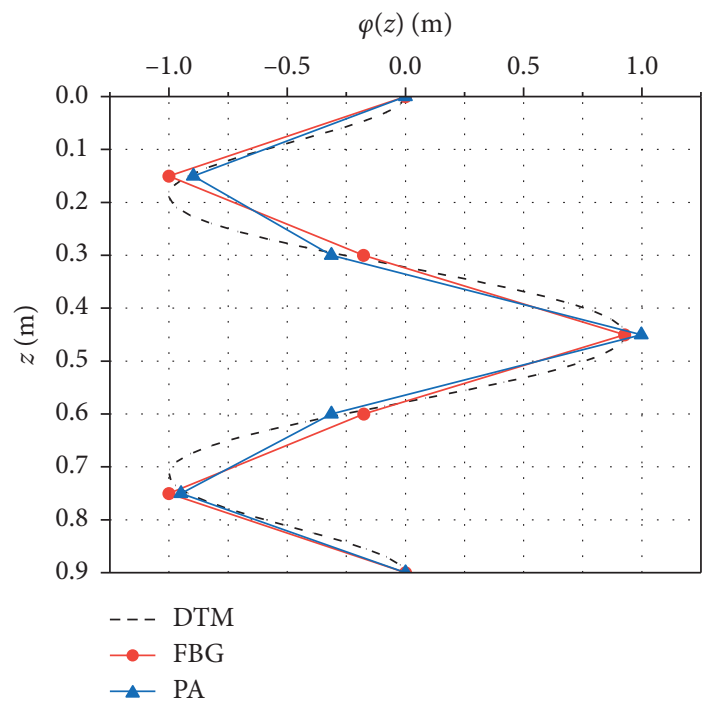

(c)

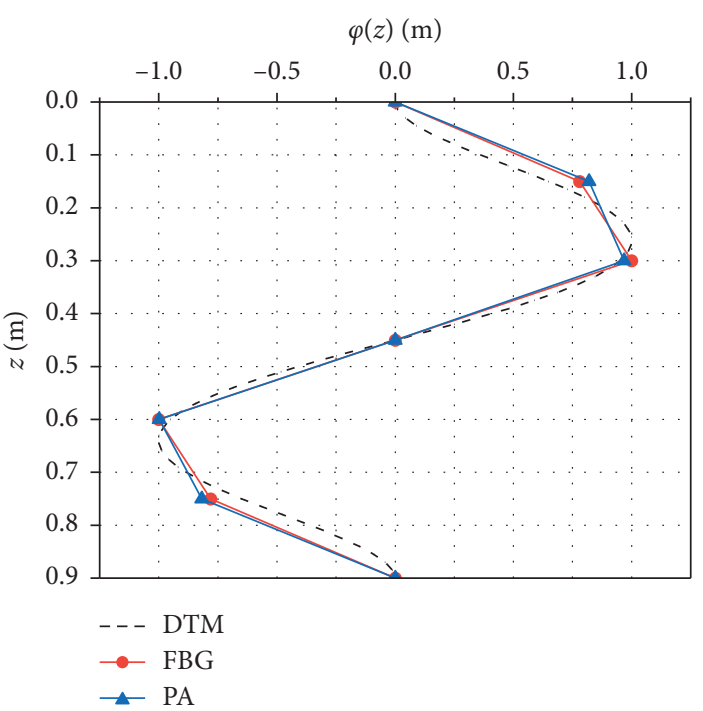

(b)

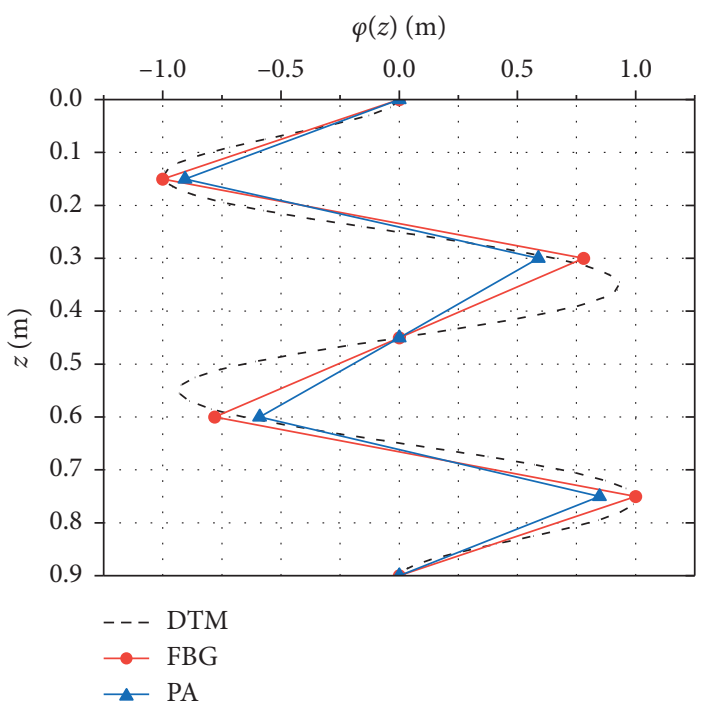

(d)

Figure 7: Continued.
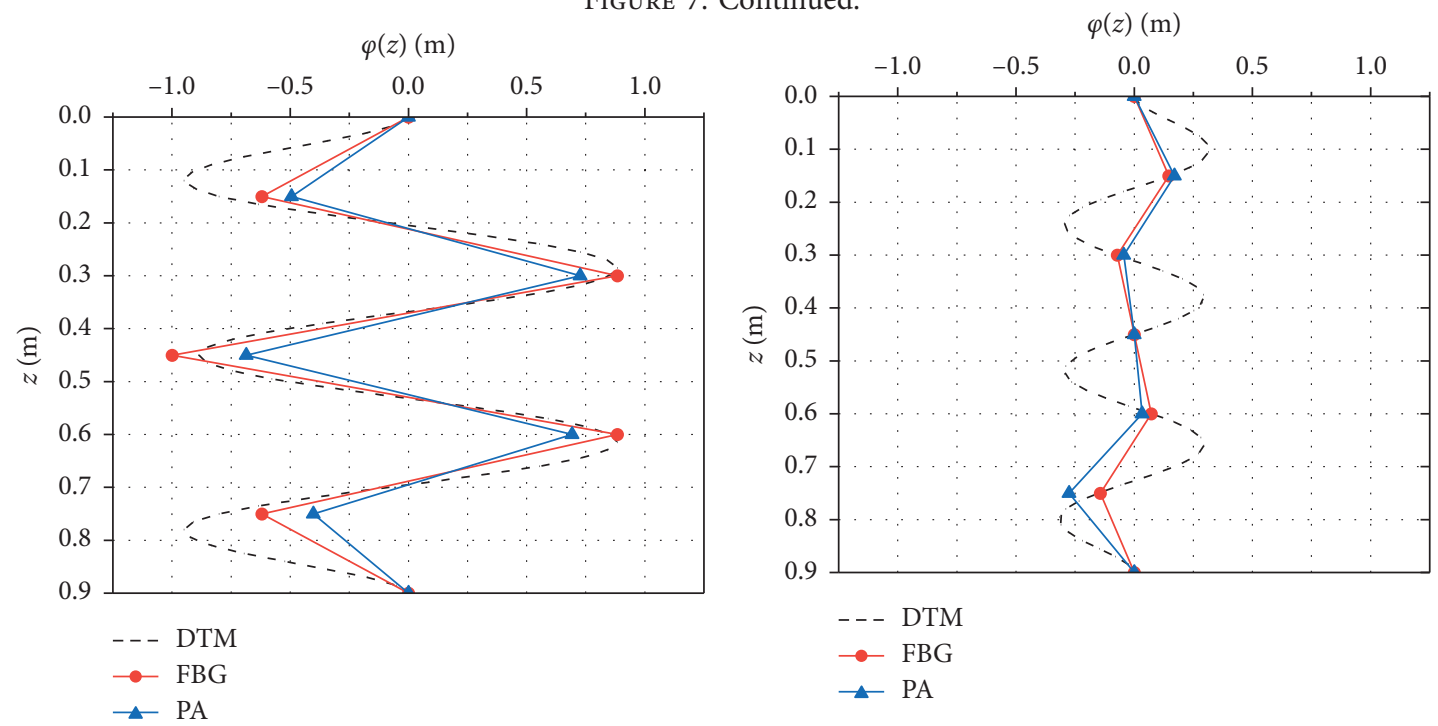

(e)

(f)

Figure 7: Mode shape of the model pipe 1: (a) first mode, (b) second mode, (c) third mode, (d) fourth mode, (e) fifth mode, and (f) sixth mode. 
TABLE 5: Known parameters.

\begin{tabular}{lc}
\hline Property & Value \\
\hline Length of the pipe $(l) \mathrm{m}$ & 1500 \\
Density of seawater $\left(\rho_{\mathrm{w}}\right) \mathrm{kg} / \mathrm{m}^{3}$ & 1025 \\
Density of drill pipe $\left(\rho_{\mathrm{s}}\right) \mathrm{kg} / \mathrm{m}^{3}$ & 7850 \\
Elastic modulus of steel $(E) \mathrm{GPa}$ & 206 \\
Outside diameter $(D) \mathrm{mm}$ & 127 \\
Thickness of pipe $(\delta) \mathrm{mm}$ & 9.19 \\
Add mass coefficient $\left(C_{\mathrm{a}}\right)$ & 1 \\
Mass of tree and tool $\left(W_{\mathrm{B}}\right) \mathrm{kg}$ & 50000 \\
\hline
\end{tabular}

TABLE 6: Results of DTM and FEM.

\begin{tabular}{lcccc}
\hline Natural frequency $(\mathrm{Hz})$ & 1st & 2nd & 3rd & 4th \\
\hline DTM & 0.01248 & 0.03769 & 0.06763 & 0.09893 \\
FEM & 0.01135 & 0.03414 & 0.06153 & 0.09011 \\
Error (\%) & 9 & 9.4 & 9 & 8.9 \\
\hline
\end{tabular}

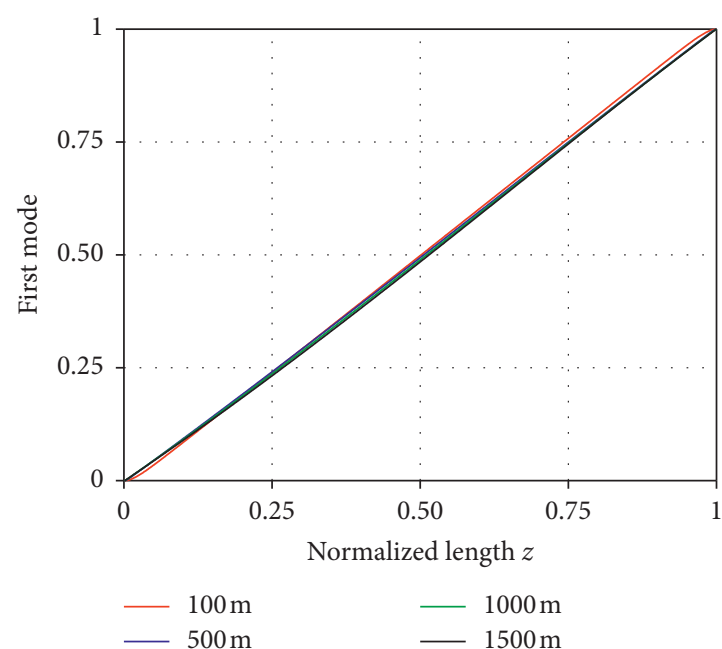

(a)

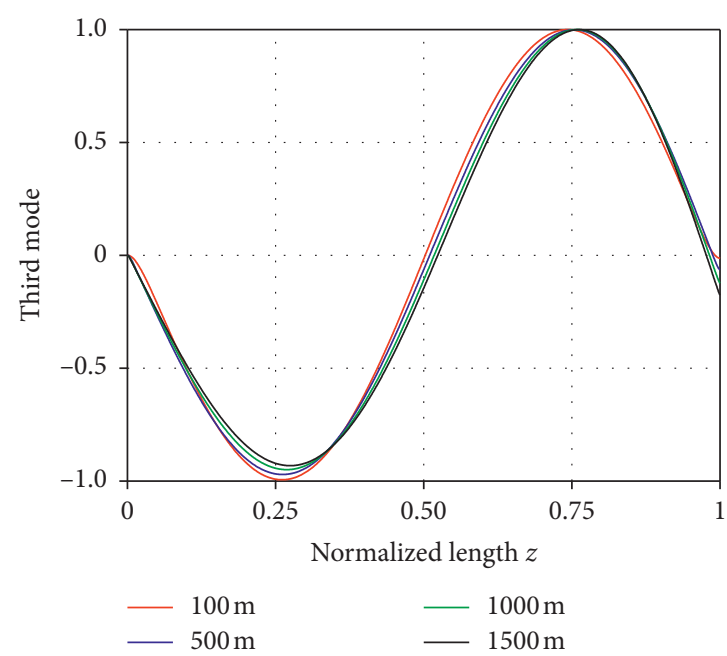

(c)

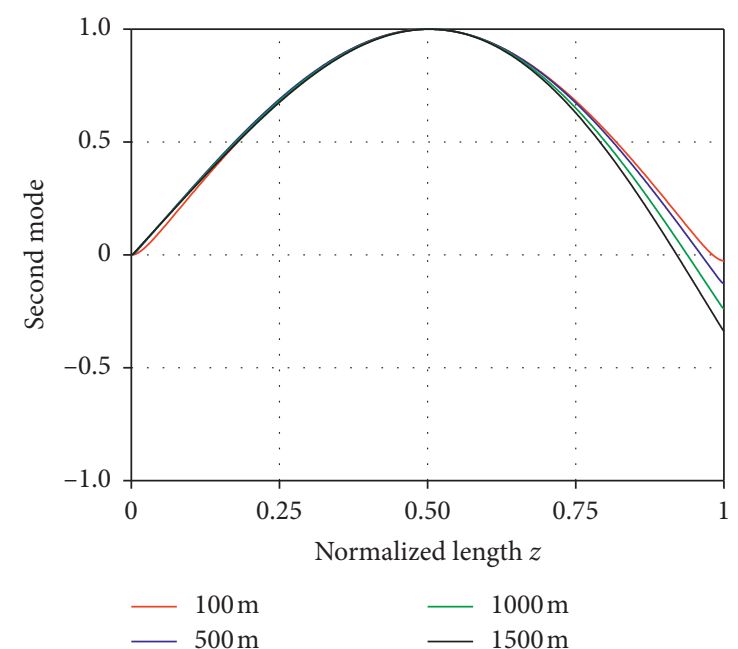

(b)

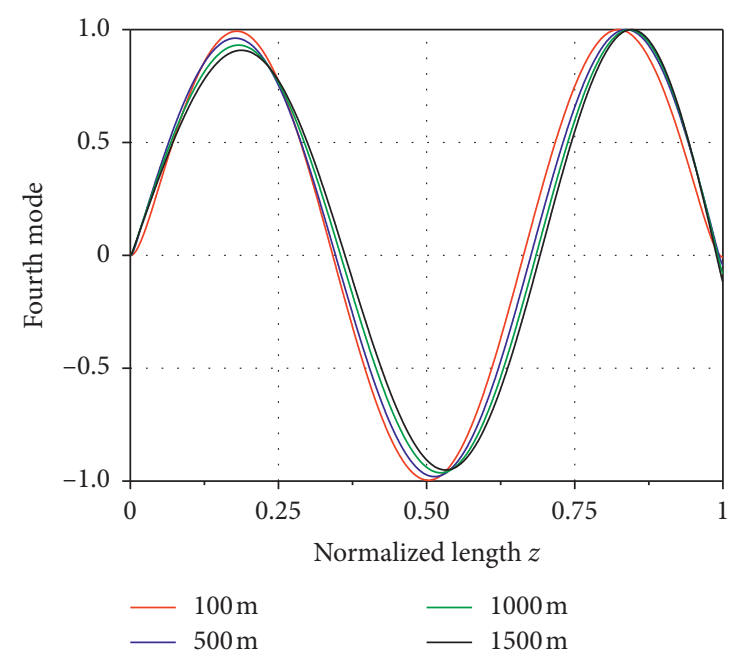

(d)

Figure 8: Mode shapes of the pipe of different lengths: (a) first mode, (b) second mode, (c) third mode, and (d) fourth mode. 


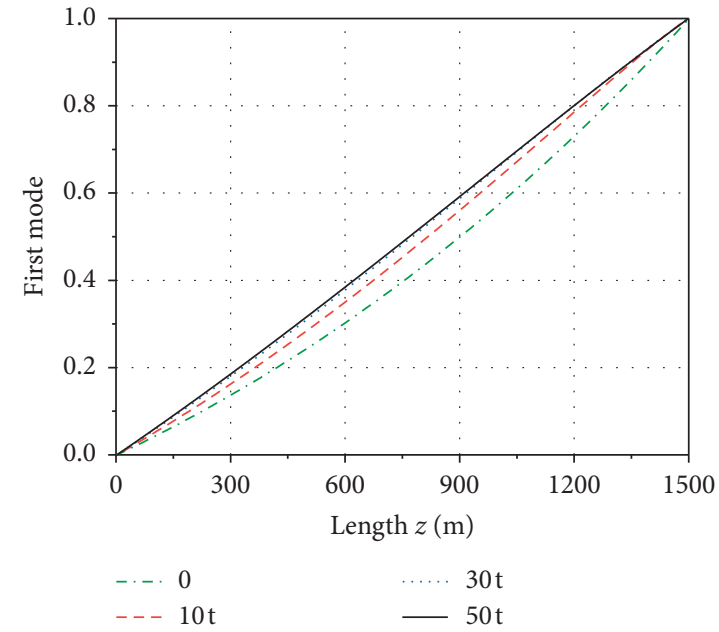

(a)

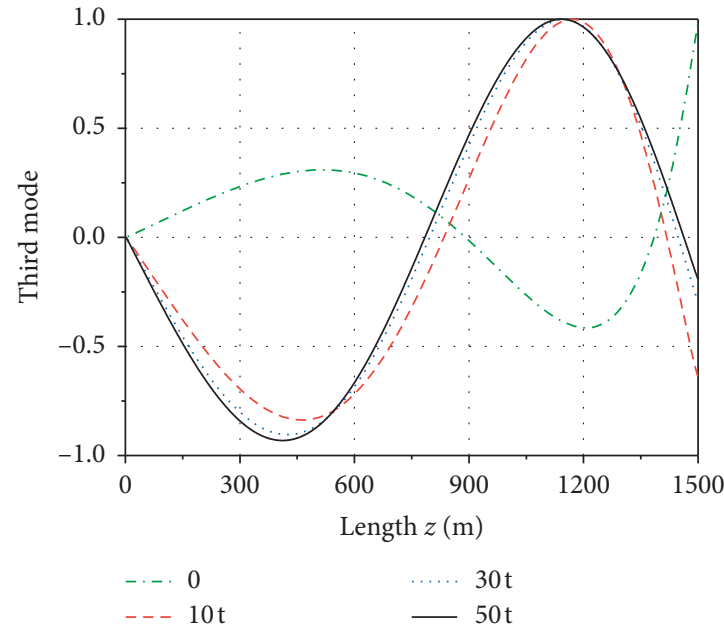

(c)

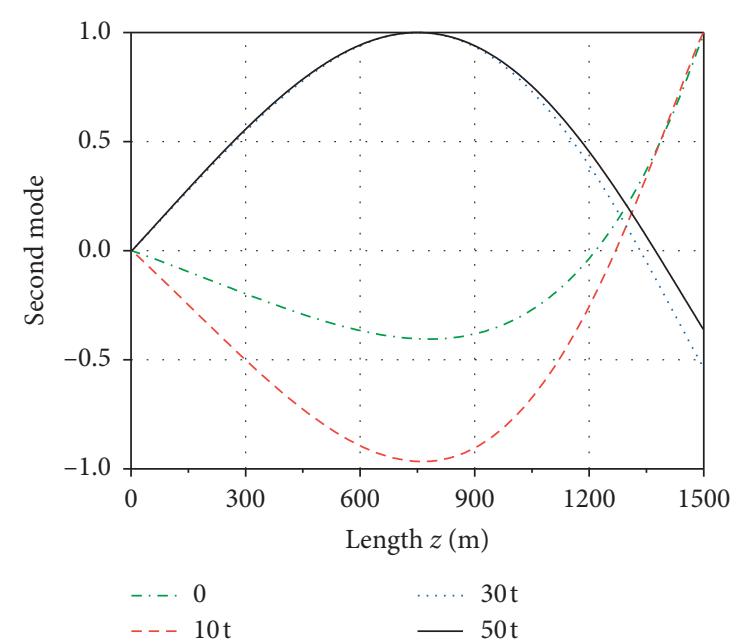

(b)

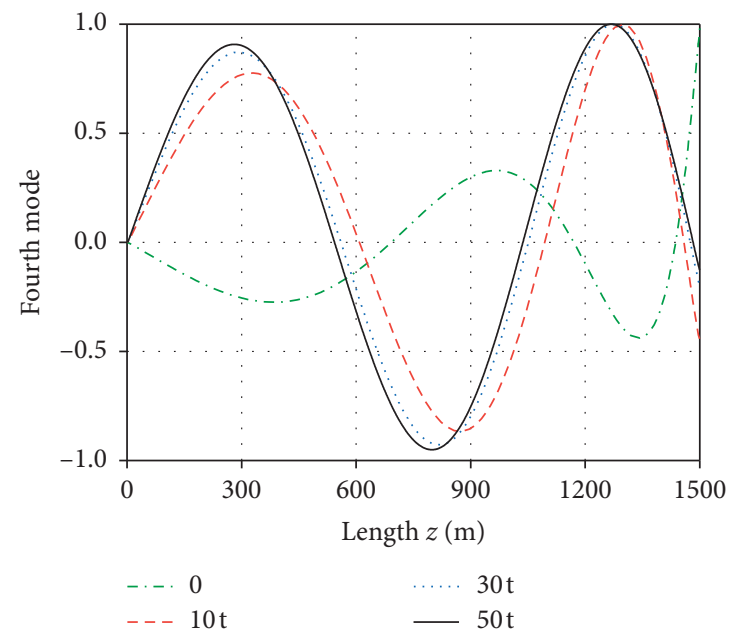

(d)

Figure 9: Mode shapes of the pipe with different weight trees: (a) first mode, (b) second mode, (c) third mode, and (d) fourth mode.

sixth-order mode shape are quite different; the measured modal amplitude is significantly smaller than the theoretically calculated amplitude because the test points are too few to show high order modes accurately.

\section{Example Calculation and Analysis}

4.1. Example. Taking an actual subsea Xmas tree installation process as an example, the known parameters are listed in Table 5:

4.2. Analysis of the Influencing Factors. Table 6 lists natural frequencies that were calculated using DTM and FEM. It can be seen from the table that results of two methods are almost same. Considering that the FEM results can be influenced by the number of finite elements, we believe that the DTM results are closer to the exact solution and more convenient for application.

As noted earlier, the mode shape of the riser can be readily determined using equation (16). Figure 8 shows the first four modes shape of the pipe with different heights. It can be seen from these figures that the mode shape of the pipe remains basically unchanged during the lowering of the tree, but a change in the length affects the mode shape only locally. The amplitude at the end of the pipe increases as the length of the drill pipe increases.

Figure 9 shows the first four mode shapes of the pipe with the Xmas tree having different weights. Under the condition a pipe with a free end, the maximum amplitude is at the end of the pipe, but after hanging the tree, the maximum amplitude does not occur at the end of the pipe. Moreover, as the weight of the tree increases, the vibration amplitude at the end of the drill pipe will decrease.

\section{Conclusions}

In this paper, the DTM is used to solve the natural frequency and mode shape of a pipe applied in the installation of a subsea Xmas tree, and the results are verified by using PA sensors and FBG sensors. Several conclusions are given as follows: 
(1) The frequency obtained using the DTM is acceptable enough for design purposes because the mean error is generally less than $5 \%$, and thus, the frequency of the pipe while lowering a subsea Xmas tree can be determined using the equations and technique proposed in this paper.

(2) According to the experiments in this paper, it can be confirmed that the natural frequency of the vertical cantilever is affected by the length of the beam and the weight of the suspended end when the material properties of the beam are constant. The natural frequency of the beam is inversely proportional to its length and the weight of bottom lumped mass. In other words, during the process of lowering of the tree, the natural frequency of the system will gradually decrease. Meanwhile, the natural frequency of the lowering system can be reduced by adjusting the added weight of the tree to avoid resonance.

(3) The length of the pipe has little influence on the mode shape, but the weight of the tree and the counterweight on the end of the pipe have considerable effects on the mode shape. Relative to a freely suspended drill pipe, the end vibration of a pipe with a lumped mass on one end is more biased towards its equilibrium position.

\section{Nomenclature}

$D: \quad$ The outer diameters of the pipe $(\mathrm{m})$

$d$ : The inner diameters of the pipe (m)

E: The modulus of elasticity $(\mathrm{Pa})$

I: $\quad$ The area moment of inertia $\left(\mathrm{m}^{4}\right)$

$l: \quad$ The length of the pipe $(\mathrm{m})$

$m_{\mathrm{B}}$ : The suspend mass at the pipe bottom $(\mathrm{kg})$

$m_{\mathrm{e}}$ : The effective mass of the pipe per unit length $(\mathrm{kg})$

$m_{\mathrm{p}}$ : The mass of the pipe $(\mathrm{kg})$

$m_{\mathrm{f}}$ : The mass of the internal fluid $(\mathrm{kg})$

$m_{\mathrm{a}}$ : The added mass $(\mathrm{kg})$

$T: \quad$ The axial tension force of the beam (N)

$t$ : The time (s)

$w$ : The net weight of the pipe per unit length $(\mathrm{N})$

$x$ : The transverse deflection of the beam axis $(\mathrm{m})$

$z$ : $\quad$ The coordinate measured along the axis of the pipe (m)

$\bar{z}: \quad$ Dimensionless parameter of length

$\delta$ : $\quad$ Thickness of pipe

$\rho_{\mathrm{s}}: \quad$ The density of the pipe $\left(\mathrm{kg} / \mathrm{m}^{3}\right)$

$\rho_{\mathrm{w}}$ : The density of seawater $\left(\mathrm{kg} / \mathrm{m}^{3}\right)$

$\rho_{\mathrm{f}}$ : The density of the internal fluid $\left(\mathrm{kg} / \mathrm{m}^{3}\right)$

$C_{\mathrm{a}}$ : The added mass factor

$\varphi(z)$ : The product of a spatial function

$\varphi(\bar{z})$ : Dimensionless parameter of transverse deflection of the pipe

$\gamma(t)$ : A temporal function

$\omega: \quad$ The natural frequency of the pipe $(\mathrm{Hz})$

$\phi(z)$ : The differential transformation of the $k$ th-order derivative of a function

$\Phi(k)$ : The $k$ th-order differential transformation

$\lambda$ : The eigenvalue.

\section{Data Availability}

The data used to support the findings of this study are available from the corresponding author upon request.

\section{Conflicts of Interest}

The authors declare that they have no conflicts of interest with respect to publication of this paper.

\section{Acknowledgments}

The authors acknowledge the Ministry of Industry and Information Technology of the PR China for their support through the project "Development of Subsea Vertical Christmas Tree" (Grant no. (2013)420). This work was also funded by National Key Research and Development Project (Grant no. 2016YFC0302900).

\section{References}

[1] Y. Bai and Q. Bai, "Chapter 19-subsea manifolds," in Subsea Engineering Handbook, Y. Bai and Q. Bai, Eds., Gulf Professional Publishing, Houston, TX, USA, pp. 571-632, 2010.

[2] Y. Wang, H. Tuo, L. W. Li, Y. Zhao, H. Qin, and C. An, "Dynamic simulation of installation of the subsea cluster manifold by drilling pipe in deep water based on orcaflex," Journal of Petroleum Science and Engineering, vol. 163, pp. 67-78, 2018.

[3] D. W. Dareing and T. Huang, "Natural frequencies of marine drilling risers," Journal of Petroleum Technology, vol. 28, no. 7, pp. 813-818, 1976.

[4] A. Soltanahmadi, "Determination of flexible riser natural frequencies using fourier analysis," Marine Structures, vol. 5, no. 2-3, pp. 193-203, 1992.

[5] M. S. Triantafyllou and A. Bliek, "The dynamics of inclined taut and slack marine cables," in Proceedings of the Offshore Technology Conference, Houston, TX, USA, May 1983.

[6] C. Sparks, "Transverse modal vibrations of vertical tensioned risers: a simplified analytical approach," Oil \& Gas Science \& Technology, vol. 57, no. 1, pp. 71-86, 2002.

[7] S. Krawczyk, "Influence of joint stiffness on the free vibration of marine riser conveying fluid," Eighth ISOPE Pacific/Asia Offshore Mechanics Symposium, vol. 55, 2008.

[8] D. J. Montoya-Hernández, A. O. Vázquez-Hernández, R. Cuamatzi, and M. A. Hernandez, "Natural frequency analysis of a marine riser considering multiphase internal flow behavior,” Ocean Engineering, vol. 92, pp. 103-113, 2014.

[9] Y. Chen, Y. H. Chai, X. Li, and J. Zhou, "An extraction of the natural frequencies and mode shapes of marine risers by the method of differential transformation," Computers \& Structures, vol. 87, no. 21-22, pp. 1384-1393, 2009.

[10] W. P. Howson and F. W. Williams, "Natural frequencies of frames with axially loaded timoshenko members," Journal of Sound and Vibration, vol. 26, no. 4, pp. 503-515, 1973.

[11] Y. Cheng, J. K. Vandiver, and G. Moe, "The linear vibration analysis of marine risers using the wkb-based dynamic stiffness method," Journal of Sound and Vibration, vol. 251, no. 4, pp. 750-760, 2002.

[12] Y. Si, K. Ye, F. W. Williams, and D. Kennedy, "Theory and algorithm of the exact method for free vibration problems of skeletal structures," Engineering Mechanics, no. S1, pp. 1-6, 2005. 
[13] L.-Y. Xi, X.-F. Li, and G.-J. Tang, "Free vibration of standing and hanging gravity-loaded rayleigh cantilevers," International Journal of Mechanical Sciences, vol. 66, pp. 233-238, 2013.

[14] L. N. Virgin, S. T. Santillan, and D. B. Holland, "Effect of gravity on the vibration of vertical cantilevers," Mechanics Research Communications, vol. 34, no. 3, pp. 312-317, 2007.

[15] T. Anye and W. Ziguo, "Natural frequencies of transverse vibration of cantilever rayleigh beams," Journal of Jishou University (Natural Science Edition), vol. 38, no. 2, pp. 26-31, 2017.

[16] F. Mirzaee, "Differential transform method for solving linear and nonlinear systems of ordinary differential equations," Applied Mathematical Sciences, vol. 5, no. 70, pp. 3465-3472, 2011.

[17] S. Shali, S. R. Nagaraja, and P. Jafarali, "Vibration of nonuniform rod using differential transform method," IOP Conference Series: Materials Science and Engineering, vol. 225, Article ID 012027, 2017.

[18] C. Mei, "Application of differential transformation technique to free vibration analysis of a centrifugally stiffened beam," Computers \& Structures, vol. 86, no. 11-12, pp. 1280-1284, 2008.

[19] S. H. Ho and C. K. Chen, "Analysis of general elastically end restrained non-uniform beams using differential transform," Applied Mathematical Modelling, vol. 22, no. 4-5, pp. 219-234, 1998.

[20] H. Qin, J. Liu, W. Xiao, and B. Wang, "Quasistatic nonlinear analysis of a drill pipe in subsea xmas tree installation," Mathematical Problems in Engineering, vol. 2019, Article ID 4241363, 9 pages, 2019.

[21] J. F. Doyle, Wave Propagation in Structures: An FFT-Based Spectral Analysis Methodology, Springer-Verlag, Berlin, Germany, 1989.

[22] I. H. A.-H. Hassan, "On solving some eigenvalue problems by using a differential transformation," Applied Mathematics and Computation, vol. 127, no. 1, pp. 1-22, 2002. 